\title{
Identification of Two Types of Metallogenic Fluids in the Ultra-Large Huize Pb-Zn Deposit, SW China
}

\author{
Yan Zhang, ${ }^{1}$ Runsheng Han, ${ }^{1}$ Pingtang Wei, ${ }^{2}$ and Lei Wang ${ }^{1}$ \\ ${ }^{1}$ Southwest Institute of Geological Survey, Geological Survey Center for Non-Ferrous Mineral Resources, Kunming University of \\ Science and Technology, Kunming 650093, China \\ ${ }^{2}$ Kunming Geological Prospecting Institute, China Metallurgical Geological Bureau, Kunming 650024, China
}

Correspondence should be addressed to Runsheng Han; 554670042@qq.com

Received 3 March 2017; Revised 27 May 2017; Accepted 4 July 2017; Published 27 August 2017

Academic Editor: Tobias P. Fischer

Copyright (C) 2017 Yan Zhang et al. This is an open access article distributed under the Creative Commons Attribution License, which permits unrestricted use, distribution, and reproduction in any medium, provided the original work is properly cited.

\begin{abstract}
This work investigates the ultra-large Huize $\mathrm{Pb}-\mathrm{Zn}$ deposit, based on the results of preceding studies and detailed field geological surveys. The existing findings were reorganized and reinterpreted and supplemented with $\mathrm{C}-\mathrm{H}-\mathrm{O}$ isotopic measurements, which resulted in the identification of two different metallogenic fluids: a high temperature, low salinity, and acidic Fluid A, which originates from deep-seated fluids and is enriched in lighter $\mathrm{C}$ and $\mathrm{O}$ isotopes $\left(-3 \%{ }_{0}<\delta^{13} \mathrm{C} \%{ }_{0}<-4 \%\right.$; $10 \% 0<\delta^{18} \mathrm{O} \%{ }_{0}<$ $17 \%$; $-92 \%$ o $<\delta \mathrm{D} \%$ o $<-50 \%$ ), and a low temperature, high salinity Fluid B, which is a subsurface brine formed by atmospheric precipitation. Fluid B is characterized by heavier $\mathrm{C}-\mathrm{O}-\mathrm{H}$ isotopic compositions $\left(-2 \%_{0}<\delta^{13} \mathrm{C} \%_{0}<1 \%\right.$; $2 \%_{0}<\delta^{18} \mathrm{O} \%{ }_{0}<24 \%$; $-66 \%$ o $\delta \mathrm{D} \%$ o $<-43 \%$ ) than Fluid A and cycles continuously within the strata. We hypothesize that the Huize Pb-Zn deposit is the result of large-scale fluid migration from deep regions of the crust. These upward-moving fluids extracted metallic elements from carbonate strata of various ages, forming a metal-rich metallogenic fluid (Fluid A). After higher-grade ores were precipitated from the fluid following decompression boiling, it then mixed with Fluid B and continued to precipitate sulfides.
\end{abstract}

\section{Introduction}

The $\mathrm{Pb}-\mathrm{Zn}$ deposits in the Sichuan-Yunnan-Guizhou $\mathrm{Pb}-\mathrm{Zn}$ polymetallic metallogenic belt (Figure 1) are mainly carbonate-type deposits. Hence, carbonate-hosted $\mathrm{Pb}-\mathrm{Zn}$ deposits are among the most important types of $\mathrm{Pb}-\mathrm{Zn}$ deposits in the mining industry. Deposits of this type are widely distributed throughout the world and are concentrated in regions such as North America, Europe, and Southeast Asia. Carbonate-hosted $\mathrm{Pb}-\mathrm{Zn}$ deposits are also the world's most important source of lead and zinc, as they single-handedly account for $25 \%$ of the world's reserves. These deposits tend to be large in scale, consistent in terms of ore quality, and straightforward to extract and smelt. The germanium-, lead-, and zinc-rich regions of Northeast Yunnan, which lie on the southwestern margin of the Yangtze Plate, are an important component of the Sichuan-Yunnan-Guizhou $\mathrm{Pb}-\mathrm{Zn}$ polymetallic metallogenic belt, which contains $221 \mathrm{~Pb}-\mathrm{Zn}$ polymetallic deposits and mineralization points. In particular, the Huize
$\mathrm{Pb}-\mathrm{Zn}$ deposit, which is located on either side of the $\mathrm{N}-\mathrm{S}$ trending Qujing-Zhaotong concealed fracture zone at the NE end of the Jinniuchang-Kuangshanchang tectonic belt, is one of the richest ultra-large $\mathrm{Ge}-\mathrm{Pb}-\mathrm{Zn}$ enriched deposits in the world [1]. The Huize deposit has a unique metallogenic system that is characterized by large reserves of lead and zinc (over $8 \mathrm{Mt}$ ) and high average ore grades $(\mathrm{Pb}+\mathrm{Zn}$ : $25 \%-35 \%$, with some exceeding $60 \%$ ) and is representative of the metallogenic zones in Sichuan, Yunnan, and Guizhou.

This particular deposit has been exhaustively studied by a number of scholars, and a series of important findings have been made in studies on the geological background of the mining areas in Northeast Yunnan [2-4], the geochemistry of the deposit [5-14], the tectonic setting of the ore fields [15-17], and the formation of the deposit [2$8,15,16,18-22]$, thus providing a wide range of resources for this study to access and build upon. While consensus has been reached on topics such as the tectonic setting of the lead and zinc deposits in the region [11, 23-27] (boundaries of a stable platform), distribution characteristics 


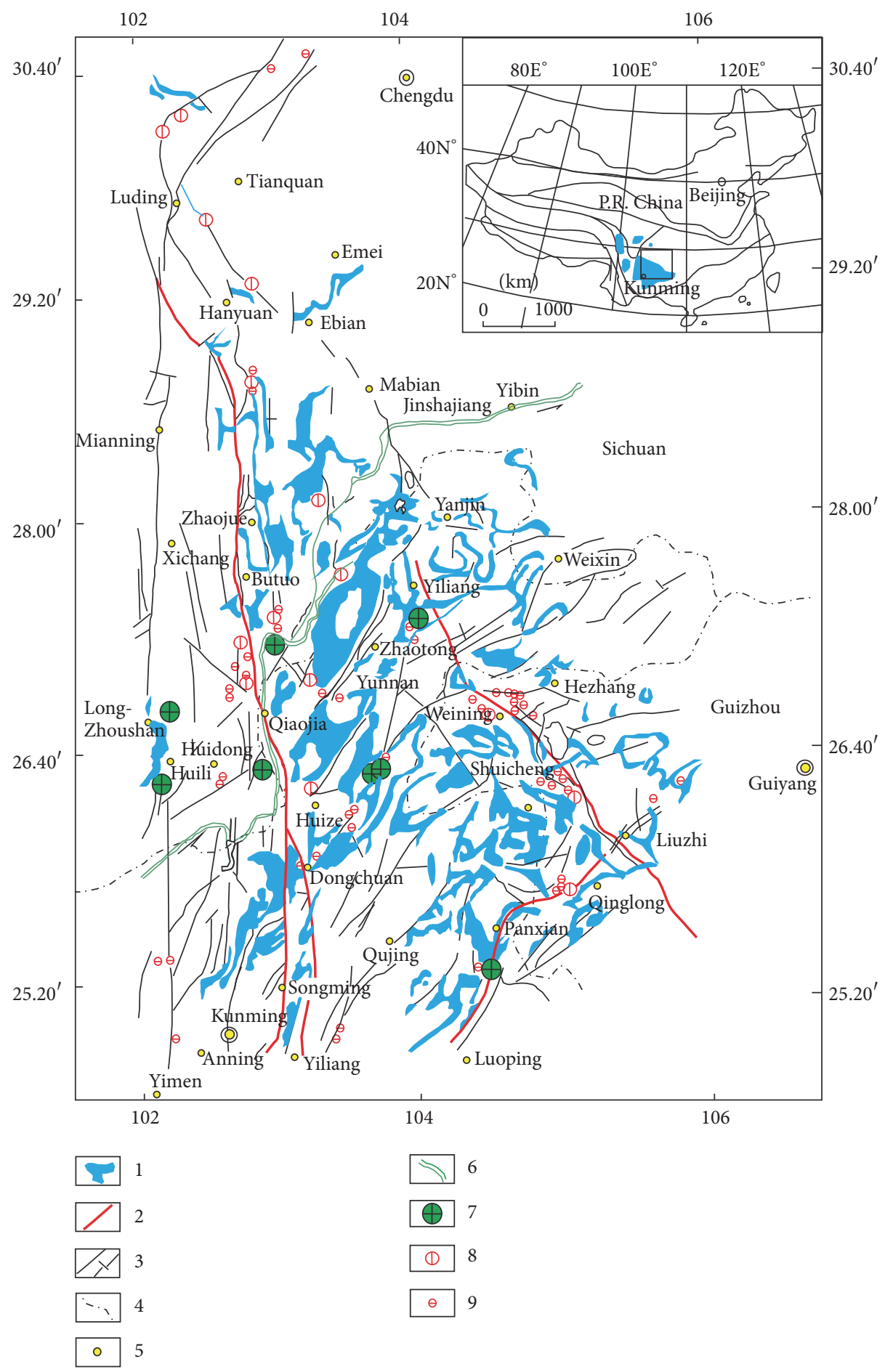

Figure 1: Tectonic map showing distribution of $\mathrm{Zn}-\mathrm{Pb}-(\mathrm{Ag}-\mathrm{Ge})$ deposits in the Sichuan-Yunnan-Guizhou triangle, SW China (modified after [23]). 1: Emeishan flood basalt; 2: main fault; 3: secondary fault; 4: province boundary; 5: town; 6: river; 7: large deposit; 8: medium deposit; 9: small deposit.

of the deposits [23, 25, 27-29] (simultaneously controlled by lithological characteristics and tectonic structure), ore host rocks $[23,25,28]$ (mainly medium-to-coarse-grained, thick-bedded dolomites), and connection between metallogenesis and large-scale fluid migration [8,30-32], significant controversies remain regarding the origin and evolution of the metallogenic fluids, which are of great importance for deposit formation models. Liu and Lin [21] believe that the metallogenic fluids are mainly derived from water that cycles through subsurface layers, and the sulfur in the deposits comes from the reduction of marine sulfates, mainly by thermochemical sulfate reduction (TSR) [10]. In contrast, 
Han et al. $[12,27]$ believe that the sulfur in the metallogenic fluids mainly originates from carbonate strata, while the fluid itself is derived from mineral-rich metamorphic waters and deep-seated thermal fluids. Analysis of several stable isotopes also revealed that the metallogenic fluids may have different origins $[8,33]$. Therefore, the origins of the metallogenic fluids in the Huize deposit remain controversial despite the comprehensive studies that have been performed in this region. It is also possible that the metallogenic fluids have undergone unique evolutionary processes.

There are also significant controversies regarding the precipitatory mechanisms of sulfides in the Huize deposit, and the current views on this matter may be categorized into the following three groups. (1) Fluid mixing: based on $\mathrm{C}-\mathrm{O}$ isotopic analysis, Huang et al. [8, 33-35] believe that the mixing of crust and mantle fluids is the key to metallogenesis; Luo et al. [36] proposed that mixing between fluids is the primary mechanism of precipitation, based on their summation of previous studies on fluid inclusions; Zhang et al. [37-40] believe that the processes of fluid mixing and boiling are the primary causes of sulfide precipitation, based on the results of studies on strontium isotopes and fluid inclusions. (2) Fluid boiling: Han et al. [12, 13, 23] performed a detailed study of the geological characteristics and fluid inclusions and came to the conclusion that fluid boiling is the primary mechanism of mineral enrichment and metallogenesis. (3) pH changes: several authors believe that sulfide precipitation is mainly caused by changes in $\mathrm{pH}$ $[7,41,42]$. Based on a review of the literature, we [43] believe that fluid mixing is very likely to be the primary mechanism of precipitation in the Huize $\mathrm{Pb}-\mathrm{Zn}$ deposit.

Nevertheless, some questions remain. For example, are there two different types of metallogenic fluids in the Huize mining region? What are the origins of these fluids, and what are their defining characteristics? These issues have yet to be studied in a thorough and systematic manner. In this work, we reorganized and reinterpreted the results of previous $\mathrm{C}, \mathrm{H}$, and $\mathrm{O}$ isotopic studies, supplemented these findings with new isotopic evidence from Kuangshanchang (which is comparatively scarce in the literature), and combined these findings with current geological information and previous studies on fluid inclusions, to discuss the origins of two different metallogenic fluids that are present in the Huize deposit, as well as their evolutionary processes. On this basis, we then hypothesized a rational process of metallogenesis for the Huize $\mathrm{Pb}-\mathrm{Zn}$ deposit.

\section{Regional Geological Setting}

The Huize $\mathrm{Pb}-\mathrm{Zn}$ mining area is located on the southwestern margin of the Yangtze Plate (Figure 1), on the western side of the Yunnan-Guizhou fold and thrust belt, in the Jinniuchang-Kuangshanchang metallogenic belt within the Dongchuan-Zhenxiong tectonic belt, in the southeastern part of the Northeast Yunnan fold-fault system. The mining area is bordered by the Weining-Langdai depressed foldfault bundle, the major Xiaojiang fracture zone on the eastern margin of the Kangdian Axis, the Niushoushan uplifted fold-fault bundle, and the Liangshan fold-fault bundle to the east, west, south, and north, respectively [44].

The regional stratigraphy is composed of Precambrian basement overlain by a sedimentary cover sequence deposited in the Late Sinian, with an angular unconformable contact between these two units. The metamorphic basement is mainly composed of the Mesoproterozoic Hekou and Huili groups, the Neoproterozoic Yanbian and Yanjing groups, and large Neoproterozoic magmatic complexes, as well as their equivalent strata. The sedimentary cover comprises marine sediments composed of strata ranging in age from Sinian to Permian and terrestrial sediments that consist of Mesozoic and Cenozoic strata.

The Sichuan-Yunnan-Guizhou $\mathrm{Pb}-\mathrm{Zn}$ polymetallic metallogenic region is located within the Huili-Kunming rift $[45,46]$ and is surrounded by deep and large faults that act as boundaries. This region is bordered by the N-S trending Anninghe-Luzhijiang Fault, Kangding-Yiliang-Shuicheng Fault, and Mile-Shizong-Shuicheng Fault to the west, north, and south, respectively [45]. The tectonic structure of this region comprises 15 faults, which may be categorized as nearNS-, NE-, and NW-trending faults (Figure 1). In particular, the N-S trending Xiaojiang Fault and Zhaotong-Qujing concealed fault play a significant role in controlling the magmatic activity in the region, as well as the distribution and development of lead, zinc, and silver deposits $[8,16]$.

Magmatic activity in the Sichuan-Yunnan-Guizhou $\mathrm{Pb}-\mathrm{Zn}$ polymetallic metallogenic region recurs frequently and persists for long periods of time, and it is known that magma outflows occurred from the Jinning Period until the Yanshan Period. Igneous rocks are distributed widely and inhomogeneously throughout this region. In particular, the Hercynian Emeishan basalts (Figure 1) are widely distributed and immensely thick and constitute the well-known Emeishan volcanic province [8].

\section{Geological Characteristics of the Huize Deposit}

The Huize deposit is located on both sides of the nearNS-trending Qujing-Zhaotong concealed fault, at the NE end of the Jinniuchang-Kuangshanchang tectonic belt. It comprises the ultra-large Kuangshanchang and Qilinchang $\mathrm{Pb}-\mathrm{Zn}$ deposits, the Yinchangpo medium-sized $\mathrm{Pb}-\mathrm{Zn}$ deposit (Guizhou), and the Longtoushan, Xiaoheiqing, and Lanyinchang $\mathrm{Pb}-\mathrm{Zn}$ mines (Figure 2).

3.1. Stratigraphy. The stratigraphy of the mining region is composed of Early Sinian metamorphic basement and Sinian and Paleozoic sediments. The upper Paleozoic strata are well-developed, while the Qiongzhusi Formation is the only Cambrian outcrop of the lower Paleozoic strata; the Middle and Upper Cambrian, Ordovician, Silurian, and Lower Devonian strata are missing, and outcrops of the Upper Sinian Dengying Formation and Middle-Upper Devonian strata only appear in localized sections. In particular, the Lower Carboniferous Baizuo Formation $\left(\mathrm{C}_{1} b\right)$ is the main ore-bearing layer. 

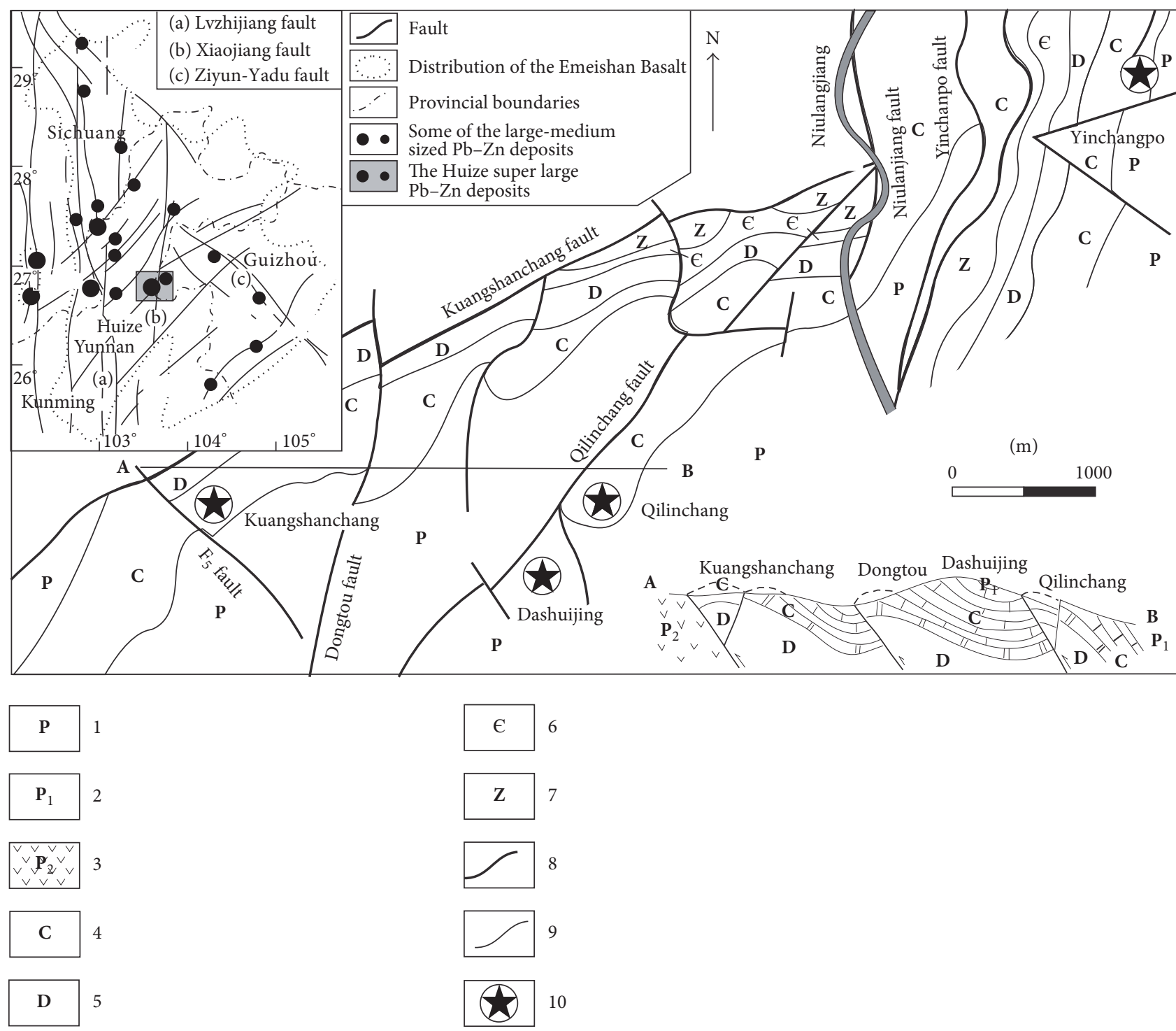

Figure 2: Geological sketch map of the Huize Pb-Zn ore deposit (modified after [16]). 1: Permian carbonate rock, Emeishan flood basalt, and shale; 2: Lower Permian Qixia-Maokou Fm. limestone and dolomitic limestones; Liangshan Fm. charcoal, shale, and sandstone; 3: Lower Permian Emeishan flood basalt; 4: Carboniferous: Maping Fm. brecciform limestone; Weining Fm. oolitic limestone; Baizuo Fm. coarsegrained dolostones and dolomitic limestones; Datang Fm. aphanitic limestone and oolitic limestone; 5: Devonian: Zaige Fm. limestone, siliceous dolostone, and dolostone; Haikou Fm. siltstone and shale; 6: Cambrian Qiongzhusi Fm. shale and sandy mudstone; 7: Sinian Dengying Fm. siliceous dolomite; 8: fault; 9: stratigraphic boundary; 10: $\mathrm{Pb}-\mathrm{Zn}$ deposit.

3.2. Tectonic Structure. The faults within the mining region mainly developed in NE, NW, near-NS, NNW, and nearEW orientations. In particular, the NE-SW-trending reverse shear faults are important ore-controlling tectonic structures. The Kuangshanchang, Qilinchang, and Yinchangpo faults form a tectonic structure comprising three imbricated layers, and as the main faults in this region, they control the Kuangshanchang, Qilinchang, and Yinchangpo deposits (Figure 2), respectively. These faults are connected by the near-NS-trending Dongtou reverse fault [16].

\subsection{Characteristics of the Orebodies}

3.3.1. Kuangshanchang Deposit. The Kuangshanchang deposit occurs within the area defined by the Kuangshanchang
Fault, F5 Fault, and Dongtou Fault (Figure 2), with the orebodies mainly occurring within the medium-to-coarsegrained dolomites of the Lower Carboniferous Baizuo Formation $\left(C_{1} b\right)$. Within a $\sim 2000 \mathrm{~m}$ long section of land, $260 \mathrm{~Pb}-\mathrm{Zn}$ orebodies of varying sizes can be found. The orebodies usually occur as sheets, lenticels, sacs, lentils, and irregular veins, and these generally propagate along interlayer fractures. Lateral end-to-end alignment of structures and expansion/contraction are usually observed along the strike and dip of the orebodies. The horizontal lengths of the orebodies range from $26 \mathrm{~m}$ to $233 \mathrm{~m}$, with an average of $98.17 \mathrm{~m}$. The horizontal widths range from $2 \mathrm{~m}$ to $35 \mathrm{~m}$, with an average of $16.65 \mathrm{~m}$, and the depths along dip exceed $1050 \mathrm{~m}$. The $\mathrm{Pb}$ grades range from $4.73 \%$ to $44.05 \%$, with an 
average of $20.60 \%$, while the $\mathrm{Zn}$ grades range from $3.29 \%$ to $46.52 \%$, with an average of $29.74 \%$. As the depth increases, the distribution of ores changes from oxidized ores to mixed ores and finally to sulfide ores.

3.3.2. Qilinchang Deposit. The Qilinchang deposit is located above the Qilinchang Fault and comprises the Qilinchang and Dashuijing mining sections. Currently, more than 70 $\mathrm{Pb}-\mathrm{Zn}$ orebodies have been discovered in this deposit (with 20 possessing industrial value). The $\mathrm{Pb}-\mathrm{Zn}$ reserves exceed $2.46 \mathrm{Mt}$, with an average $(\mathrm{Zn}+\mathrm{Pb})$ ore grade of $25 \%$. All of the ores occur within the coarse-grained dolomites and limestones in the middle and upper sections of the Lower Carboniferous Baizuo Formation $\left(\mathrm{C}_{1} b\right)$. The boundaries between the orebodies and the host rocks are very distinct, and the orebodies are generally formed along interlayer fractures, with some ores produced in certain locations at low angles with respect to the strata. The orebodies have a strike of $20-30^{\circ} \mathrm{NE}$ and a steep dip of $50-76^{\circ} \mathrm{SE}$. They also have a short horizontal length and great depth along dip. In the horizontal plane, the orebodies occur as sheets, stratoids, veins, sacs, flat columns, or stockworks; in the vertical plane, the ores are primarily present as lenticels, with thinning or pinched branches at the top and tail ends.

3.4. Ore and Mineral Characteristics. The Huize $\mathrm{Pb}-\mathrm{Zn}$ deposit mainly contains sulfide and oxide ores. Currently, most of the ores extracted from the deposit are sulfide ores. The mineral composition of the sulfide ores is relatively simple and mainly comprises sphalerite, galena, and pyrite, with sporadic occurrences of chalcopyrite, matildite, and native antimony. The host rocks are mainly calcite and dolomite, followed by quartz, barite, gypsum, and clay-type materials.

The main ore structures consist of massive, disseminated, banded, veined, stockwork, miarolitic, and brecciated structures (Figure 3). The primary ore textures comprise euhedral-anhedral-grained, metasomatic, edge-shared, voidfilling, poikilitic, slaty cleavage, skeletal, exsolution, graphic, crumpled, and cataclastic textures (Figure 4).

Based on the findings of previous studies [16] and this work on the macroscopic characteristics, ore structures, and textures, and mineral assemblage characteristics of the deposit, the metallogenesis of this deposit can be divided into two periods: hydrothermal metallogenesis and supergene oxidation. The hydrothermal metallogenesis stage may be further divided into four metallogenic stages: the pyrite (sphalerite) stage, sphalerite-galena stage, galena-sphalerite stage, and pyrite-carbonate stage (Figures 5 and 6). A study by Wang [47] also demonstrated that the barite veins produced within (or on either side of) the Kuangshanchang and Qilinchang faults are usually cemented with various forms of dolomite (e.g., medium-fine-grained, coarse-grained pinhole). This indicates that barites are formed by fluids that fill voids along fractures, and these are likely to be an early product of metallogenesis.

The alteration of adjacent rocks within the deposits is relatively simple, and the alteration processes (Figure 7) mainly include dolomitization, calcitization, and pyritization, with silification and argillation also occurring over a smaller distribution range. The simultaneous emergence of combinations of these alteration types is an important indicator for locating prospective deposits.

3.5. Mineralogenetic Epoch. The reported timing for the metallogenic epoch of the Huize deposit varies greatly in the literature. Based on the results of $\mathrm{Pb}$ isotope-based age modeling, Liu and Lin [21] concluded that metallogenesis occurred during the Hercynian and Yanshan periods. In contrast, Zhang [3] and Chen [18] concluded that the metallogenic epoch occurred during the Sinian to Permian, from analyses based on sedimentary mineralization. Huang et al. [33] obtained ages of 225-226 Ma from isochron dating of $\mathrm{Rb}-\mathrm{Sr}$ in sphalerite and Sm-Nd in calcite. Han et al. [24] applied geological deductions in combination with the screening of tectonic deformations and chronology constraints from isotope dating and came to the conclusion that the thrust fault and fold orogenesis occurred during the same period as $\mathrm{Pb}-\mathrm{Zn}$ metallogenesis, thus placing the metallogenic epoch in the Late Indosinian (200-230 Ma).

\section{Methods}

4.1. Sample Collection. Although a large accumulation of data already exists on the isotope geochemistry of the ultra-large Huize $\mathrm{Pb}-\mathrm{Zn}$ deposit, most of these studies have focused on the Qilinchang deposit. While some samples have been obtained from the Kuangshanchang deposit, these samples are lacking in representativity. Hence, we chose the 15th stope of tunnel $1752 \mathrm{~m}$ in Kuangshanchang as the primary focus (Figure 8) for $\mathrm{C}-\mathrm{H}-\mathrm{O}$ isotopic measurements in this work. We combined our findings with previous studies on fluid inclusions and systematically investigated the origins of the metallogenic fluids, in order to identify the two fluids that are present in the mixed metallogenesis of the Huize deposit. Fifteen dolomite samples and five calcite samples were obtained for $\mathrm{C}-\mathrm{O}$ isotopic analysis following the selection of monomineralic rocks from the 17 dolomite or limestone samples that were acquired for this study.

Through the collection and organization of data from previous studies, it was found that the $\mathrm{H}$ and $\mathrm{O}$ isotopes in the Huize deposit were sourced from the $\mathrm{H}$ of calcite fluid inclusions and mineralic $\mathrm{O}$. The calculated $\delta^{18} \mathrm{O}$ of the fluid may not be truly representative of the actual isotopic composition of the original metallogenic fluid because of issues such as the selection of the isotope equilibrium temperature and uncertainties in the equilibrium fractionation of mineralwater oxygen isotopes. Furthermore, calcites are products of the late stages of metallogenesis and lack information on the early stages of metallogenesis. Therefore, calcite samples are incapable of indicating the evolution of metallogenic fluids during different stages of metallogenesis. In this study, the macroscopic characteristics of orebodies were observed in the field, followed by rough division of the metallogenic stages. Microscopic identifications and hand specimen studies were then performed in a laboratory based on paragenetic sequences, textures, structures, and intercalation relationships, from which the ages of the selected monomineralic 


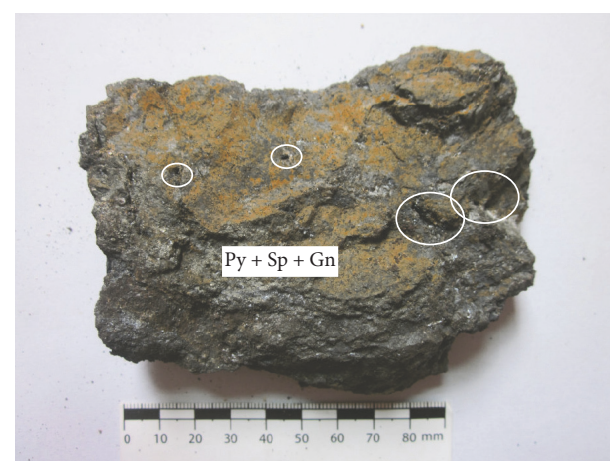

(a)

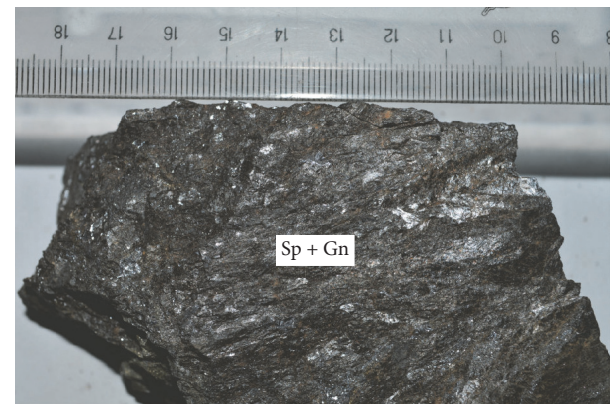

(c)

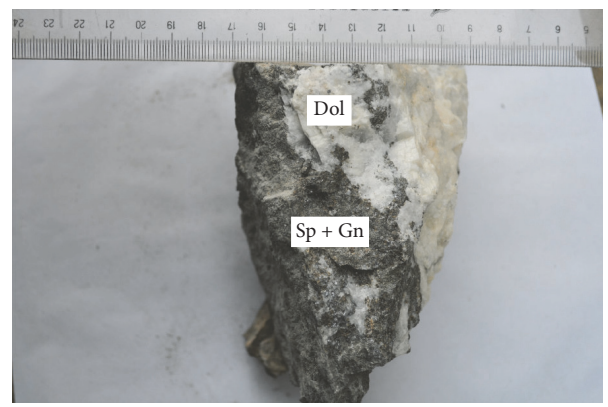

(e)

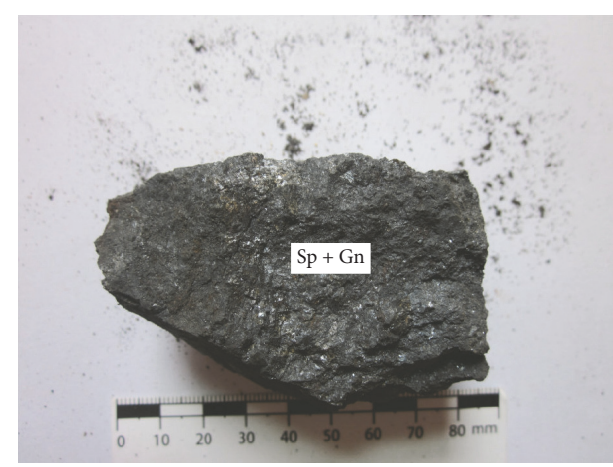

(b)

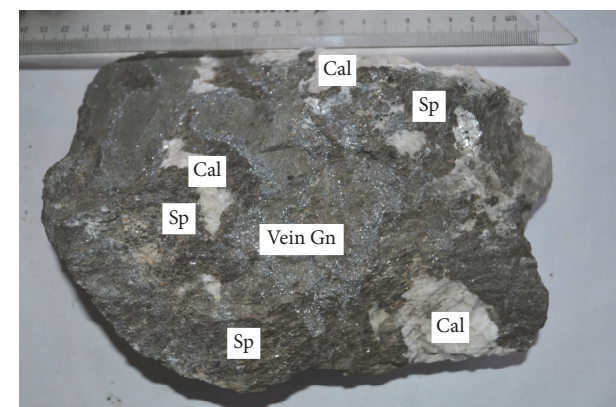

(d)

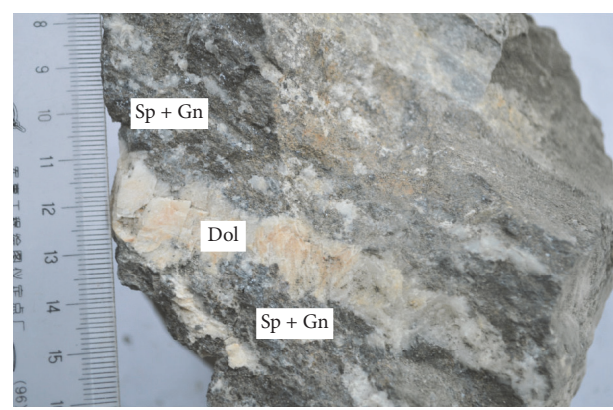

(f)

Figure 3: Typical structure photographs of minerals in the Huize Pb-Zn deposit. (a) Massive ore, miarolitic structure. (b) Dense massive ore, massive structures. (c) Massive ore, massive structures. (d) Massive ore, vein structure. (e) Disseminated ore, disseminated structures. (f) Banded structure. Sp: sphalerite; Gn: galena; Py: pyrite; Dol: dolomite; Cal: calcite.

sphalerite samples were determined. Finally, three samples were selected from each of the stages (I-III) for a total of nine samples, and these samples were used for the measurements of fluid inclusion $\mathrm{H}$ and $\mathrm{O}$ isotopes in sphalerites. To track the processes of metallogenic fluid evolution in a comprehensive manner, we examined ten stage $\mathrm{I}_{1}$ barite samples (Figure 9).

As barite is widely distributed throughout the $\mathrm{Pb}-\mathrm{Zn}$ deposits in Huize, Maozu, and Jinshachang, we also performed $\mathrm{H}-\mathrm{O}$ isotopic measurements on the barites in the Huize mining area. In the periphery of the Huize mining area, barites are mainly distributed within the Kuangshanchang Fault and the Zhujiayakou section of tunnel $1571 \mathrm{~m}$ in the Qilinchang deposit (Figure 9). In the former, barites are distributed within four veins or clots that take on irregular shapes and the shape of sacs and veins, while the barites occur as white nodules, sheets, and slabs that are distributed within calcitic and debritic dolomite cements, with developments of stockwork calcites. In the latter, the barites mainly occur as white nodules, radial growths, and veins within light-fleshcolored coarse-grained dolomites.

4.2. C-O Isotopic Analysis Method. C-O isotope analyses were carried out by ALS Minerals. Pulverized samples of carbonate were placed in borosilicate glass vials sealed with butyl rubber septa and reacted with concentrated phosphoric acid at $72^{\circ} \mathrm{C}$ for at least $1 \mathrm{~h}$ in a heated aluminum block. The evolved $\mathrm{CO}_{2}$ gas was then conducted to an LGR Analyzer (Los Gatos Research, model 908-0021), which utilizes off-axis integrated cavity output spectroscopy (OA-ICOS), and the carbon and oxygen isotope ratios were measured and recorded from the absorption spectra of ${ }^{12} \mathrm{C}^{16} \mathrm{O}^{16} \mathrm{O}$, ${ }^{13} \mathrm{C}^{16} \mathrm{O}^{16} \mathrm{O}$ and ${ }^{12} \mathrm{C}^{16} \mathrm{O}^{18} \mathrm{O}$ in the near-infrared wavelength region. 


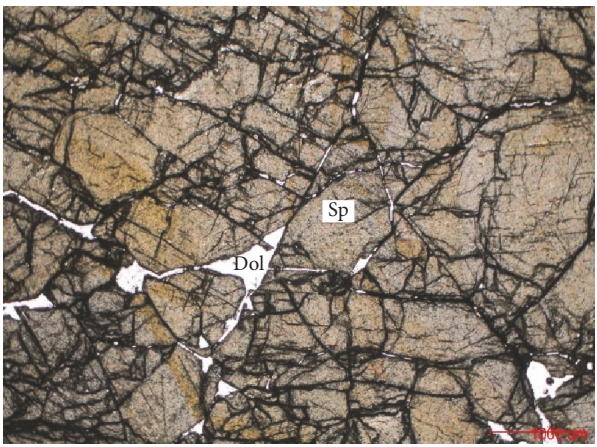

(a)

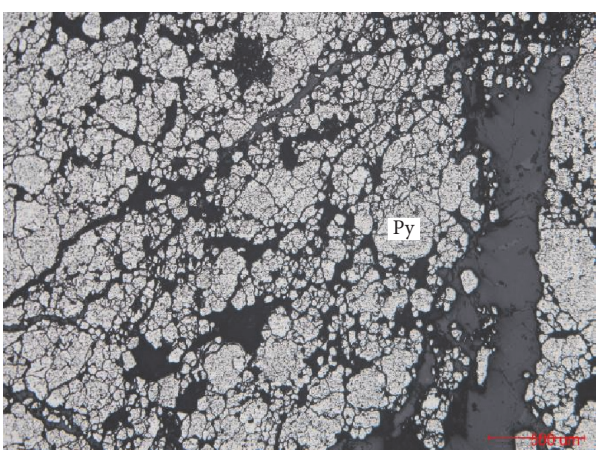

(c)

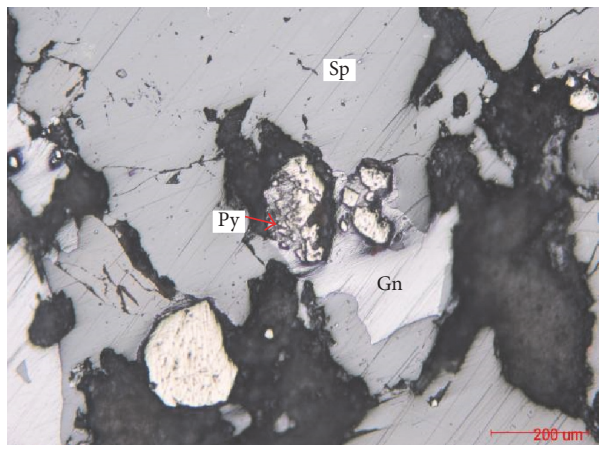

(e)

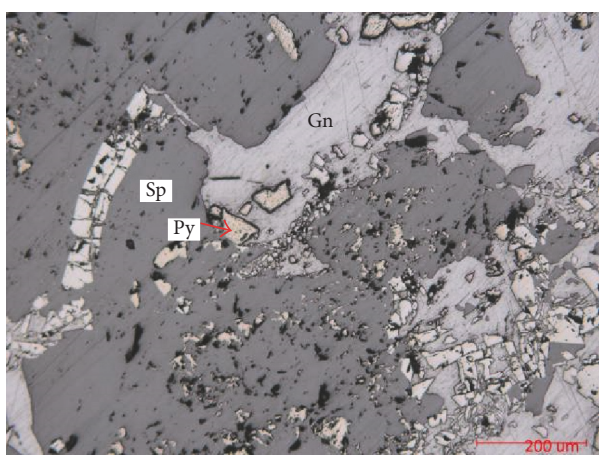

(g)

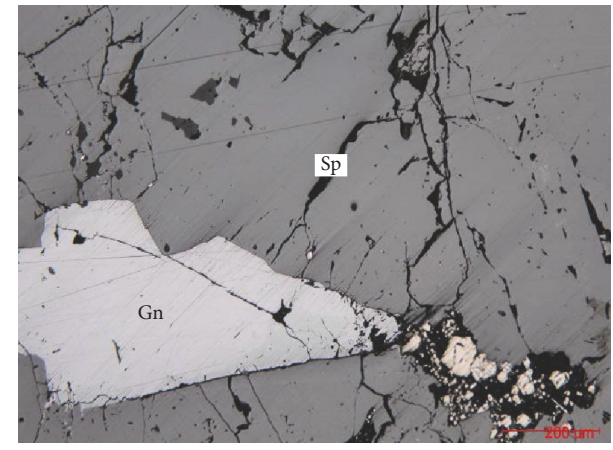

(b)

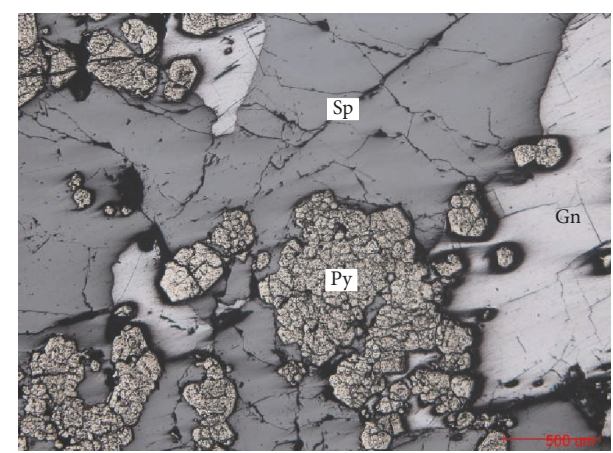

(d)

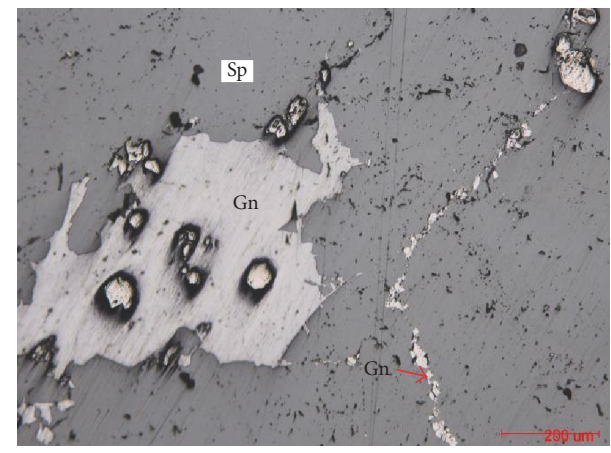

(f)

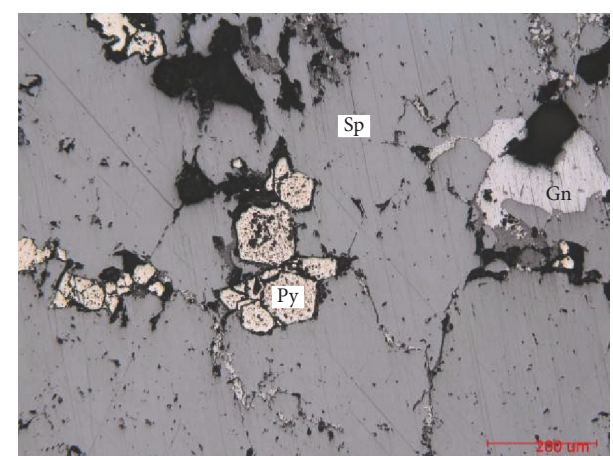

(h)

Figure 4: Typical texture photographs of minerals in the Huize Pb-Zn deposit. (a) Xenomorphic granular texture of Sp, (-)10 $\times 10$. (b) Hypidiomorphic-xenomorphic granular textures of Sp and Gn, $(-) 10 \times 2$. (c) Cataclastic texture of Py, $(-) 10 \times 4$. (d) Edge-shared texture between Sp and Gn, $(-) 10 \times 4$. (e) Skeleton crystal structure of Gn replacing Py, $(-) 10 \times 10$. (f) Metasomatic texture of Gn, $(-) 10 \times 10$. (g) Harbor structure of $\mathrm{Gn}$ replacing Sp, $(-) 10 \times 10$. (h) Inclusion structure of Py, (-) $10 \times 10$. Sp: sphalerite; Gn: galena; Py: pyrite; Dol: dolomite; Cal: calcite. 


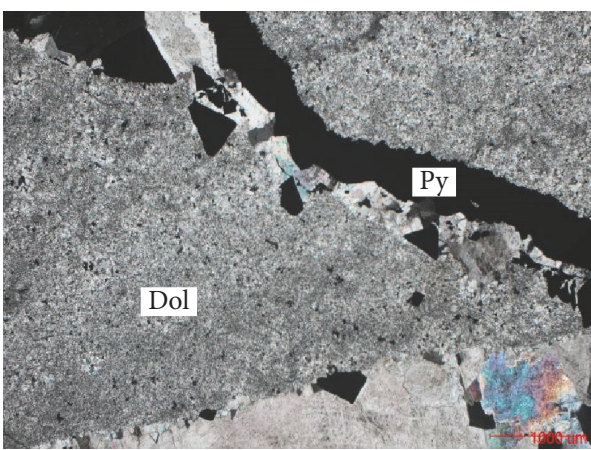

(a)

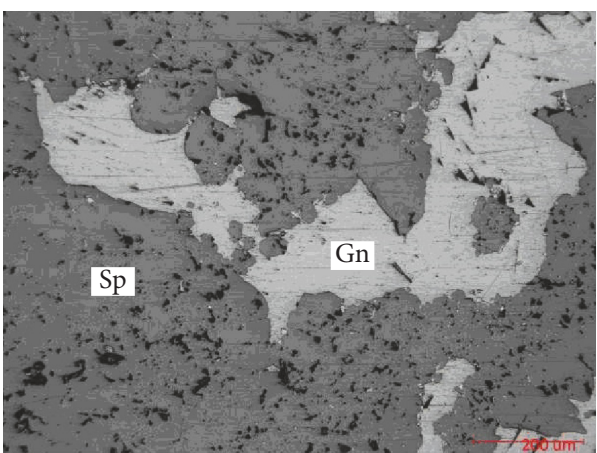

(c)

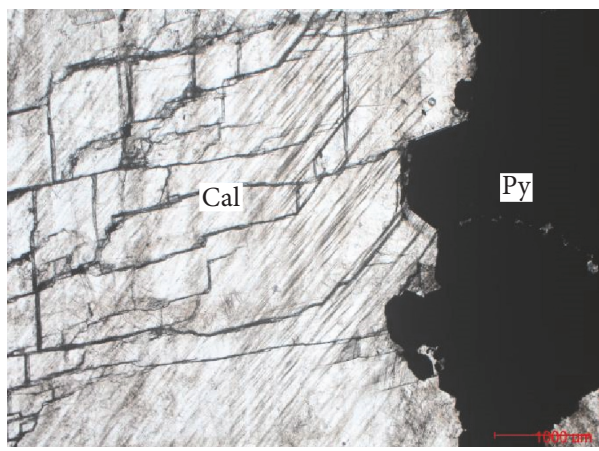

(e)

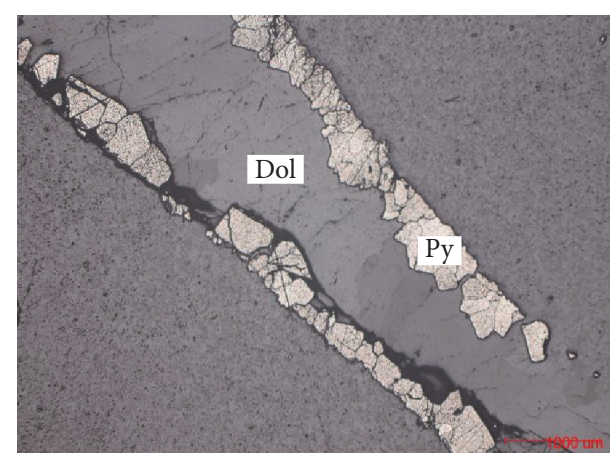

(b)

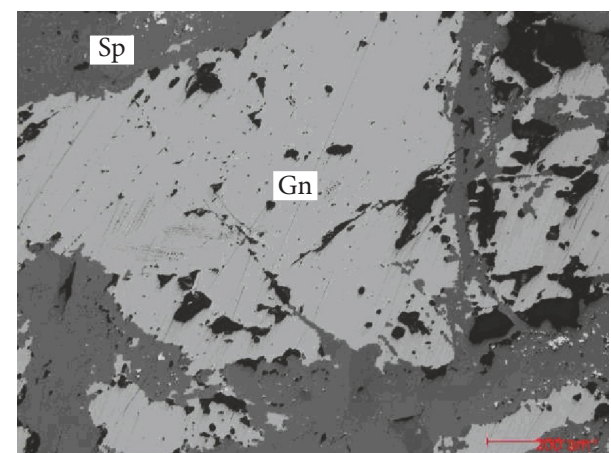

(d)

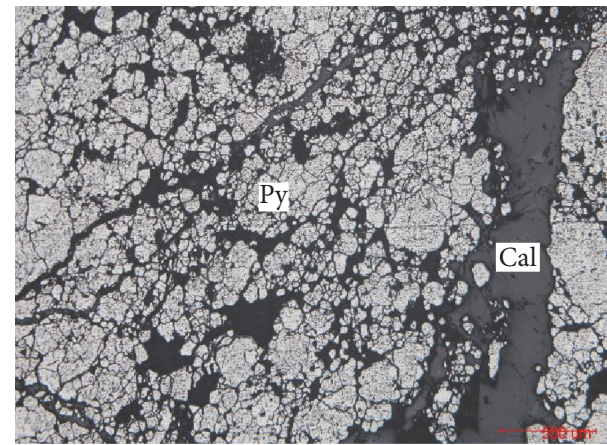

(f)

Figure 5: Typical photographs of the mineral-forming sequence of the Huize Pb-Zn deposit. (a, b) Coarse-grained Py stage (Stage I); (a) $(+) 10 \times 2$; (b) $(-) 10 \times 2$. (c) Sp-Gn stage (Stage II): edge-shared texture between Sp and Gn; the sphalerite content is far greater than galena. (d) Gn-Sp stage (Stage III): harbor structure of Gn replacing Sp; Gn is the main mineral. (e, f) Fine-grained Py-Dol-Cal stage (Stage IV); (e) $(+) 10 \times 2$; (f) $(-) 10 \times 4$. Sp: sphalerite; Gn: galena; Py: pyrite; Dol: dolomite; Cal: calcite.

The instrument was calibrated using standard $\mathrm{CaCO}_{3}$ minerals known as the Vienna Pee Dee Belemnite (VPDB) for $\delta^{13} \mathrm{C}$ and Vienna Standard Mean Ocean Water (VSMOW) for $\delta^{18} \mathrm{O}$, which had been previously calibrated by isotope ratio mass spectrometry relative to the international isotopic standards NBS18 and NBS19. Individual analyses were demonstrated to have an internal precision of better than $0.05 \%$ for $\delta^{13} \mathrm{C}$ and $\delta^{18} \mathrm{O}$.

4.3. H-O Isotopic Analysis Method. Data on calcite samples from the late stages of metallogenesis were compiled from previous studies, while data on $I_{1}$ barite samples were obtained from our measurements. The $\mathrm{H}$ isotope ratios in both sets of samples were determined through hydrogen gases generated from the zinc reduction of water (the samples were baked at low temperatures $\left(100^{\circ} \mathrm{C}-120^{\circ} \mathrm{C}\right)$ for $3 \mathrm{~h}$ to remove all adsorbed water and secondary inclusions), while $\mathrm{O}$ isotope analyses were carried out using the $\mathrm{BrF}_{5}$ technique. $\delta^{18} \mathrm{O}_{\mathrm{H} 2 \mathrm{O}}$ of the calcites were obtained from the conversion of $\delta^{18} \mathrm{O}_{\text {calcite, }}$ using the formula: $1000 \ln _{\text {Calcite }}-\mathrm{H}_{2} \mathrm{O}=4.01$ $\times 106 / T^{2}-4.66 \times 103 / T+1.71$ [50], where the temperatures $T$ and $T^{2}$ are the homogenization temperature of the calcite fluid inclusions and the average measured temperature of the sulfur isotopes $\left(200^{\circ} \mathrm{C}\right)$, respectively. $\delta^{18} \mathrm{O}_{\mathrm{H} 2 \mathrm{O}}$ values of the barites were calculated using $1000 \ln \alpha_{\text {Barite }}-\mathrm{H}_{2} \mathrm{O}=3.01$ $\times 106 / T 2-7.30$, and the temperature data required for this calculation were taken from the fluid inclusion temperature data of the corresponding samples. 


\begin{tabular}{|c|c|c|c|c|c|c|}
\hline \multirow{3}{*}{$\begin{array}{l}\text { Periods } \\
\text { Stages }\end{array}$} & \multicolumn{5}{|c|}{ Hydrothermal } & \multirow{3}{*}{$\begin{array}{c}\text { Supergene } \\
\text { oxidizing }\end{array}$} \\
\hline & \multicolumn{2}{|c|}{ I stages } & \multirow{2}{*}{ II stages } & \multirow{2}{*}{ III stages } & \multirow{2}{*}{ IV stages } & \\
\hline & $\mathrm{I}_{1}$ stages & $\mathrm{I}_{2}$ stages & & & & \\
\hline $\begin{array}{l}\text { Mineral } \\
\text { assemblage }\end{array}$ & $\begin{array}{c}\text { Brt }+ \\
\text { ferrodolomite }\end{array}$ & $\begin{array}{c}\text { Coarse grain Py }+ \\
\text { a little dark } \\
\text { brown } \mathrm{Sp}\end{array}$ & $\begin{array}{c}\text { Brown Sp + } \\
\text { Gn }+ \\
\text { ferrodolomite }\end{array}$ & $\begin{array}{c}\text { Gn }+ \text { brown, } \\
\text { light yellow } \\
\text { Sp }+ \text { Qtz }+\mathrm{Cal}\end{array}$ & $\begin{array}{c}\text { Fine grain Py } \\
\text { Dol }+ \text { Cal }\end{array}$ & \\
\hline \multicolumn{7}{|l|}{ Pyrite } \\
\hline \multicolumn{7}{|l|}{ Sphalerite } \\
\hline \multicolumn{7}{|l|}{ Galena } \\
\hline \multicolumn{7}{|l|}{ Chalcopyrite } \\
\hline \multicolumn{7}{|l|}{ Acanthite } \\
\hline \multicolumn{7}{|l|}{ Cerargyrite } \\
\hline \multicolumn{7}{|l|}{ Freibergite } \\
\hline \multicolumn{7}{|l|}{ Matildite } \\
\hline \multicolumn{7}{|l|}{ Dolostone } \\
\hline \multicolumn{7}{|l|}{ Calcite } \\
\hline \multicolumn{7}{|l|}{ Ferrodolomite } \\
\hline \multicolumn{7}{|l|}{ Quartz } \\
\hline \multicolumn{7}{|l|}{ Barite } \\
\hline \multicolumn{7}{|l|}{ Gypsum } \\
\hline \multicolumn{7}{|l|}{ Hemimorphite } \\
\hline \multicolumn{7}{|l|}{ Cerusite } \\
\hline \multicolumn{7}{|l|}{ Siderite } \\
\hline \multicolumn{7}{|l|}{ Limonite } \\
\hline Mineral structure & & $\begin{array}{c}\text { Massive, } \\
\text { disseminated }\end{array}$ & $\begin{array}{l}\text { Dense } \\
\text { massive }\end{array}$ & $\begin{array}{l}\text { Dense } \\
\text { massive }\end{array}$ & $\begin{array}{l}\text { Vein, dense } \\
\text { massive }\end{array}$ & $\begin{array}{c}\text { Earthy, } \\
\text { honeycomb }\end{array}$ \\
\hline Mineral texture & & $\begin{array}{l}\text { Coarse } \\
\text { grain, } \\
\text { metaso- } \\
\text { matism, } \\
\text { mosaic, } \\
\text { crushing }\end{array}$ & $\begin{array}{l}\text { Coarse-medium } \\
\text { grain, } \\
\text { metasomatism, } \\
\text { interstitial, } \\
\text { common edge, } \\
\text { including }\end{array}$ & $\begin{array}{c}\text { Medium-fine } \\
\text { grain, } \\
\text { metasomatism, } \\
\text { interstitial, } \\
\text { kneading, } \\
\text { kneading }\end{array}$ & $\begin{array}{l}\text { Fine grained } \\
\text { euhedral }\end{array}$ & Jelly \\
\hline Mineral type & & Py-Sp ore & $\begin{array}{l}\text { Py-Sp- } \\
\text { Gn ore }\end{array}$ & Gn-Sp ore & Py ore & $\begin{array}{l}\mathrm{Pb}-\mathrm{Zn} \\
\text { oxide ore }\end{array}$ \\
\hline
\end{tabular}

Figure 6: Mineral paragenesis of the Huize Pb-Zn deposit, SW China. Modified from Han et al. [16]. Sp: sphalerite; Gn: galena; Py: pyrite; Dol: dolomite; Cal: calcite; Brt: barite; Qtz: quartz.

$\mathrm{H}-\mathrm{O}$ isotope analyses were also carried out by ALS Minerals. For hydrogen isotope analysis (with $\mathrm{H}$ in inclusions), the sorted 40 mesh sphalerite samples were baked at low temperatures $\left(100^{\circ} \mathrm{C}-120^{\circ} \mathrm{C}\right)$ to remove adsorbed water and secondary fluid inclusions in the minerals and loaded into a zero-blank autosampler. The hydrogen isotopic composition was measured using a Thermo Finnigan thermal combustion elemental analyzer (TC/EA) coupled to a Thermo Finnigan Delta Plus XP continuous-flow isotope ratio mass spectrometer (CF-IRMS). Values of $\delta^{2} \mathrm{H}$ are reported using delta $(\delta)$ notation in permil units $(\%)$ relative to VSMOW, with a precision of $3 \%$.

For oxygen isotope analysis (with $\mathrm{O}$ in inclusions), the sorted 40 mesh sphalerite samples were baked at low temperatures $\left(100^{\circ} \mathrm{C}-120^{\circ} \mathrm{C}\right)$ to remove adsorbed water and secondary fluid inclusions in the minerals and loaded into tin capsules and placed in a Thermo Scientific TC/EA hightemperature conversion elemental analyzer, then heated to $1450^{\circ} \mathrm{C}$, and cracked to release the fluid inclusions in the form of gas. The extracted oxygen reacts with carbon rods in the furnace to produce $\mathrm{CO}$, which is analyzed for ${ }^{18} \mathrm{O} /{ }^{16} \mathrm{O}$ using a Thermo Finnigan MAT 253 stable isotope ratio mass spectrometer. Values of $\delta^{18} \mathrm{O}$ were calculated by normalizing the ${ }^{18} \mathrm{O} /{ }^{16} \mathrm{O}$ ratio in the sample to that in the VSMOW international standard. Values are reported using the delta $(\delta)$ notation in permil units (\%o) and are normally reproducible to $0.2 \%$. 


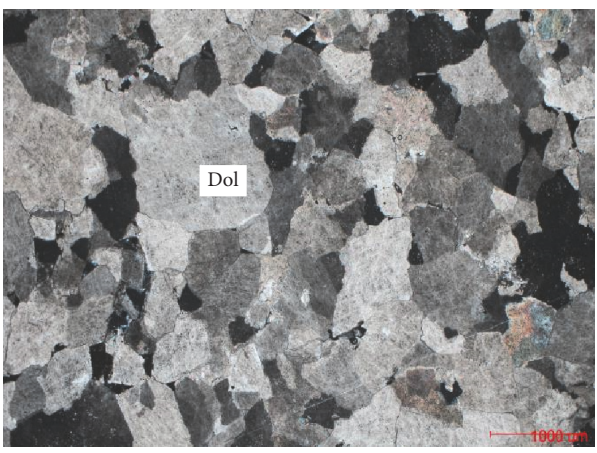

(a)

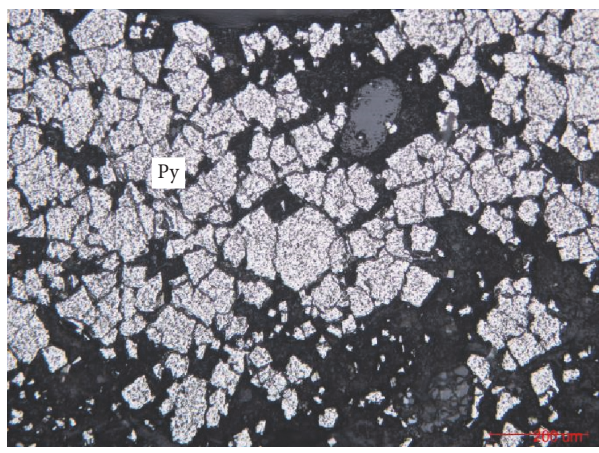

(c)

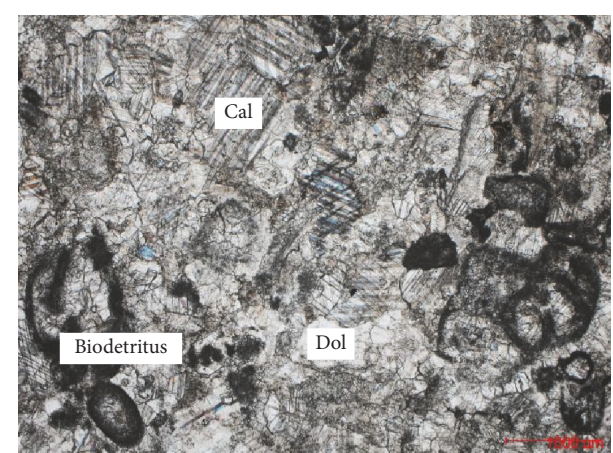

(b)

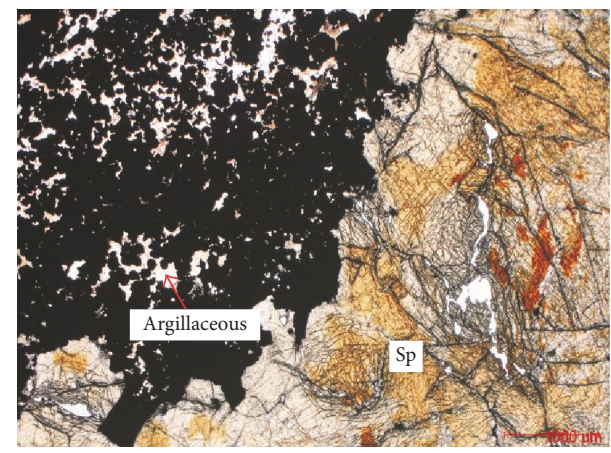

(d)

FIGURE 7: Photographs of adjacent rock alterations. (a) Dolomitization, coarse-grained structures are shown in the dolomites, $(+) 10 \times 2$. (b) Weakly dolomitized recrystallized sparitic limestone, in which the dolomites are present as euhedral-to-semieuhedral diamond-shaped crystals, and significant recrystallization is shown in the calcites, $(-) 10 \times 2$. (c) Pyritization, with the pyrites presented as euhedral-anhedral grains, $(-) 10 \times 10$. (d) Argillation, with the clay substances occurring as cryptocrystalline microflakes with grain sizes smaller than $0.02 \mathrm{~mm}$ and gaps interspersed between opaque minerals, $(-) 10 \times 2$. Sp: sphalerite; Py: pyrite; Dol: dolomite; Cal: calcite.

\section{Measurements and Reinterpretation of Existing Results}

5.1. $\mathrm{C}-\mathrm{O}$ Isotopes. It is well known that the measurement of $\mathrm{C}$ and $\mathrm{O}$ isotope compositions is an effective method for tracing the origins of $\mathrm{CO}_{2}$ within metallogenic fluids [50]. We obtained the $\mathrm{C}-\mathrm{O}$ isotopic compositions of 83 samples through our measurements, as well as from the reorganization of relevant data from the literature (Table 1).

Figure 10 shows that the $\mathrm{C}-\mathrm{O}$ isotopic compositions of the Huize $\mathrm{Pb}-\mathrm{Zn}$ deposit have the following characteristics:

(1) The C-O isotopic compositions of the Huize $\mathrm{Pb}-\mathrm{Zn}$ deposit are relatively homogeneous. The $\delta^{13} \mathrm{C}_{\mathrm{PDB}}-\delta^{18} \mathrm{O}_{\mathrm{SMOW}}$ maps (Figure 10(a)) show that the isotopic compositions cluster within a narrow range between magmatic carbonates and marine carbonates, with the compositions edging closer to those of marine carbonates. The isotopic compositions, as a whole, display the following order of isotopic values: $\delta^{13} \mathrm{C}_{\text {calcite }}<\delta^{13} \mathrm{C}_{\text {altered dolomite }}<\delta^{13} \mathrm{C}_{\text {dolomite }}<\delta^{13} \mathrm{C}_{\text {limestone }}$ and $\delta^{18} \mathrm{O}_{\text {calcite }}<\delta^{18} \mathrm{O}_{\text {altered dolomite }}<\delta^{18} \mathrm{O}_{\text {dolomite }}<$ $\delta^{18} \mathrm{O}_{\text {limestone. The }} \delta^{18} \mathrm{O}$ values of the Mid-to-Late Devonian marine limestones are mainly distributed around $20 \% \pm$, with $\delta^{13} \mathrm{C}=0 \pm$. The average $\delta^{18} \mathrm{O}$ and $\delta^{13} \mathrm{C}$ values of limestones found in the Huize mining area are equivalent to these values, which decrease as dolomitization increases. However, the $\delta^{18} \mathrm{O}$ and $\delta^{13} \mathrm{C}$ isotopic compositions of calcite are noticeably different from those of the Mid-to-Late Devonian marine limestones, as the calcite $\delta^{18} \mathrm{O}$ and $\delta^{13} \mathrm{C}$ values of the orebodies and tectonic belts are clearly lower than those in the adjacent carbonate rocks.

(2) Similar C-O isotopic compositions were observed for gangue calcites in different orebodies and calcites with different occurrences, with $\delta^{13} \mathrm{C}_{\mathrm{PDB}}$ values that vary within $-1.9 \%$ to $-3.5 \%$ and $\delta^{18} \mathrm{O}_{\mathrm{SMOW}}$ values varying within $16.8 \% 0-18.7 \%$. This indicates that the metallogenic fluid has a $\delta^{13} \mathrm{C}$ value that is much lower than that of the host rocks.

(3) The altered dolomites and bioclastic limestones of Kuangshanchang, carbonates from strata in the periphery of the mining area, and miarolitic calcites have similar $\mathrm{C}-\mathrm{O}$ isotopic compositions, with most of these compositions projecting within the region of marine carbonates. This indicates that the source of carbon in these rocks is innate to the carbonate strata in this region, as their $\mathrm{C}-\mathrm{O}$ isotopic compositions indicate that the carbon was produced via leaching of adjacent rocks by fluids, which is significantly different from calcites found in ores of the Huize deposit.

(4) The $\mathrm{C}-\mathrm{O}$ isotopic compositions of calcites from the NE-trending tectonic belt are similar to those of gangue calcites, which is distinctly different from the $\mathrm{C}-\mathrm{O}$ isotopic compositions of the previously described rock strata. This is because the main channel through which the metallogenic fluids of the Huize $\mathrm{Pb}-\mathrm{Zn}$ deposit pass is the NE-trending 


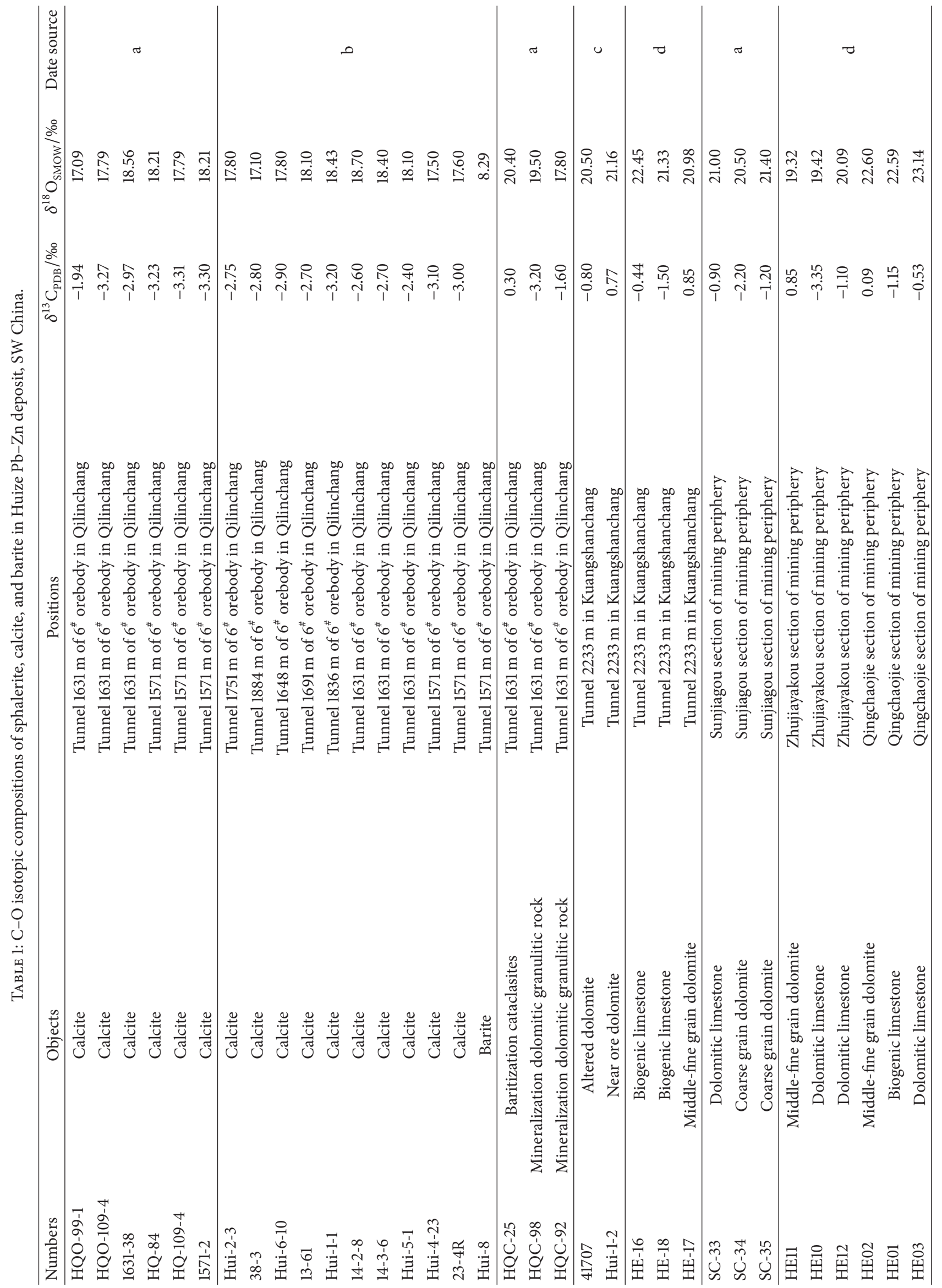




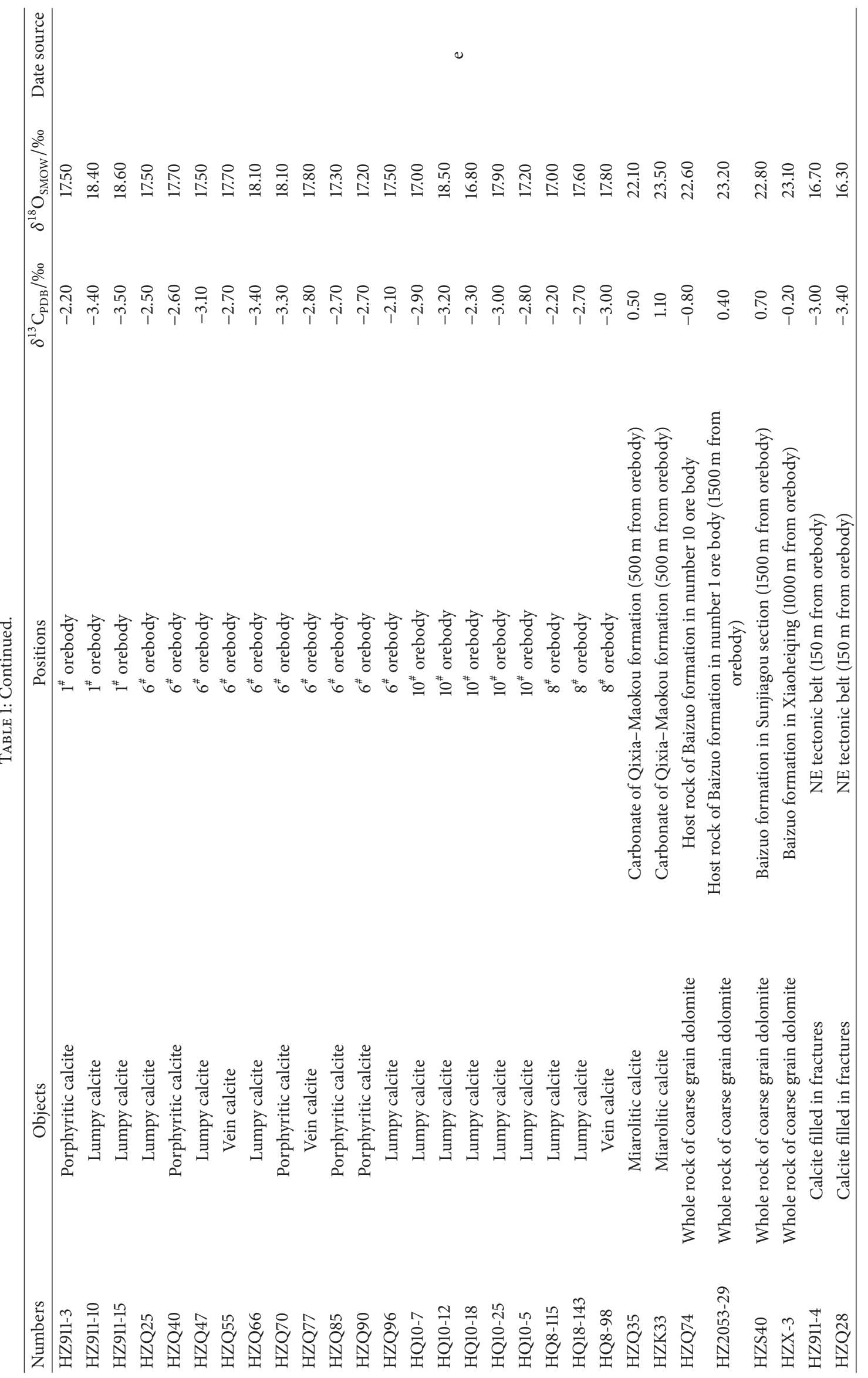




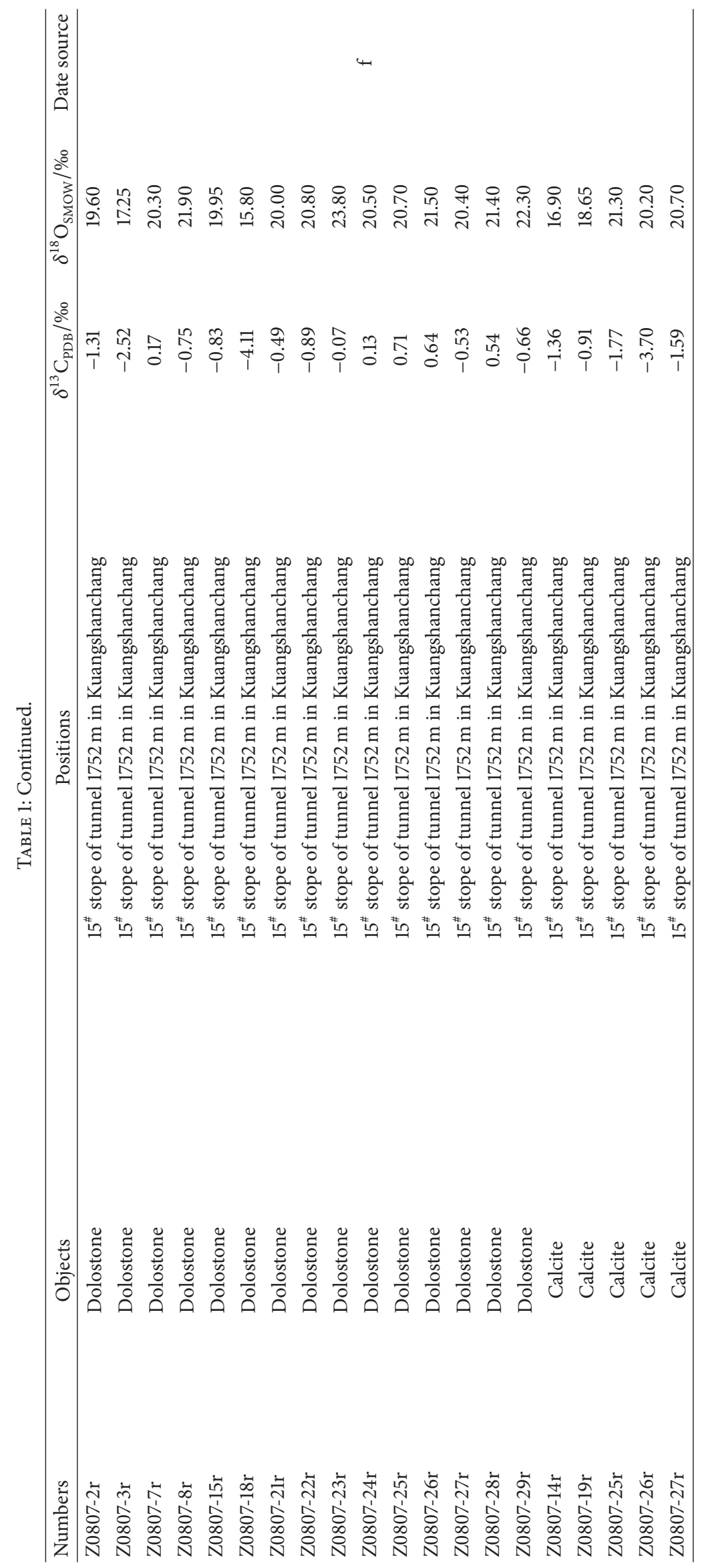




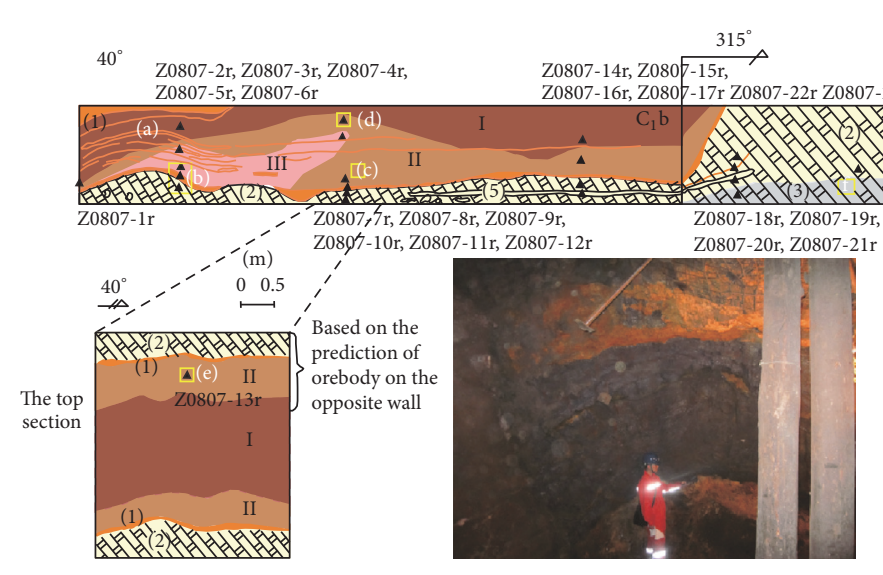

(a)

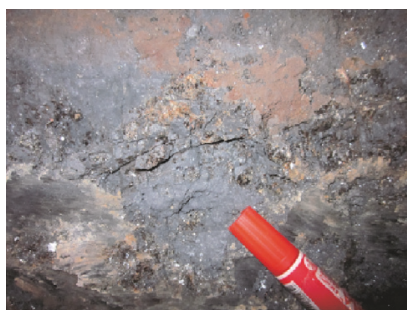

(d)

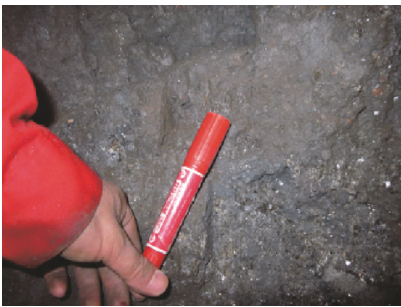

(e)

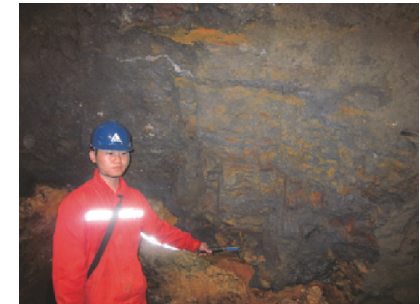

(b)

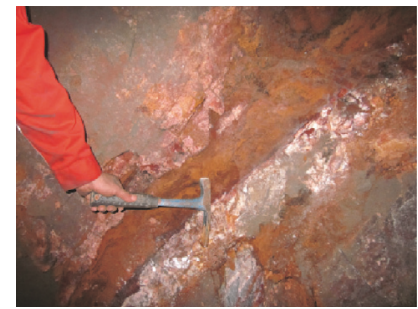

(f) (cm)

0100

NE $45^{\circ} \angle 40^{\circ} \mathrm{SE}$

FIGURE 8: Documentation and sampling of Stope 15\# in tunnel $1752 \mathrm{~m}$ in Kuangshanchang. (1) Oxidized Pb-Zn orebodies; (2) beige dolomites, with veined, porphyritic calcite developments; (3) light grey-to-grey-white medium-grained calcitic dolomite; (4) grey-to-dark-grey finegrained limestones; (5) calcite. I. First stage ores are mainly coarse-grained pyrites with small quantities of deep brown sphalerites; II. Second stage ores are mainly brown sphalerites with small amounts of galena; III. Third stage ores, rose-colored sphalerite + galena. (a) Morphology of the orebody 0-5 m above head height in Stope 15\# of tunnel $1752 \mathrm{~m}$. Yellow-brown and reddish-brown $\mathrm{Pb}-\mathrm{Zn}$ oxide orebodies were found on either side of the grey-black $\mathrm{Pb}-\mathrm{Zn}$ sulfide ores, while yellow coarse-grained dolomites lie outside the ores. Several vein-shaped oxide ores were intercalated within the sulfide orebodies. (b) Morphology of the orebody $4 \mathrm{~m}$ into Stope $15 \#$ of tunnel $1752 \mathrm{~m}$. The joint fractures are more developed in this area, the oxide orebodies formed through leaching, and sulfide orebodies occur in alternating layers. The top part of this wall is composed of ocher-red carbonates that are likely to have been produced during the later stages of hydrothermal metallogenesis. (c) Bottom part of the sulfide orebody $8 \mathrm{~m}$ into Stope $15 \#$ of tunnel $1752 \mathrm{~m}$. The main mineral in this orebody is coarse-grained pyrite, with sporadic occurrences of deep-red sphalerites. (d) Top part of the sulfide orebody on the left wall, $8 \mathrm{~m}$ into Stope \#15 of tunnel $1752 \mathrm{~m}$. The main minerals in the orebody are yellow-brown to brown sphalerites, followed by galena. The sphalerites are distributed in porphyritic and vein-like shapes, with lead-grey star-like points of galena tightly associated with the sphalerite. (e) Sulfide orebody on the right wall, $8 \mathrm{~m}$ into Stope \#15 of tunnel $1752 \mathrm{~m}$, which we deduce to be the top part of the orebody, based on its occurrence. The main minerals found in this orebody are lead-grey-colored galena, followed by yellow-brown-colored sphalerite. The galena displays a porphyritic, vein-like distribution, while the sphalerites display a vein-like, spotted distribution. (f) Morphology of an oxide orebody and its adjacent rocks, $19.5 \mathrm{~m}$ into Stope $15 \#$ in tunnel $1752 \mathrm{~m}$. (g) Interstratum fracture $46 \mathrm{~m}$ into Stope $15 \#$ of tunnel $1752 \mathrm{~m}$. The surface of the fracture has a relaxed wave-like shape, and the fracture is $1-10 \mathrm{~cm}$ wide, is filled with yellow-brown fault gouge, and displays schistosity. This fracture acts as the boundary between the $\mathrm{C}_{1} b$ and $\mathrm{C}_{1} d$ strata. The hanging wall is composed of $\mathrm{C}_{1} b$ light grey-to-grey white calcitic fine-grained dolomite, while the footwall is composed of $\mathrm{C}_{1} d$ grey-to-dark grey limestone breccia cemented with clay, which appears to be lenticularized. The fracture is a left-lateral reverse shear fracture, with an orientation of $\mathrm{NE} 45^{\circ} \angle 40^{\circ} \mathrm{SE}$.

tectonic belt $[15,21,33,51]$. Therefore, the $\mathrm{C}-\mathrm{O}$ isotopic compositions of the calcites in this tectonic belt plot closest to those of the metallogenic fluid.

(5) In the source region of the metallogenic fluid or organic matter-rich strata below the orebodies penetrated by the fluid, water-rock reactions will solvate adjacent carbonates and cause an exchange of $\mathrm{C}-\mathrm{O}$ isotopes between the fluid and the strata. This ultimately causes $\delta^{13} \mathrm{C}$ of the fluid to increase and $\delta^{13} \mathrm{C}$ of the adjacent rocks to decrease.

5.2. H-O Isotopes. As $\mathrm{H}_{2} \mathrm{O}$ is an important component of metallogenic fluids, it is important to elucidate the source of $\mathrm{H}_{2} \mathrm{O}$ in order to investigate the origin of the metallogenic fluid. The $\mathrm{H}$ and $\mathrm{O}$ isotopic compositions of gangue minerals, ore minerals, and their related alteration minerals are the most direct and effective indicators of the source of $\mathrm{H}_{2} \mathrm{O}$ in metallogenic fluids. The $\delta \mathrm{D}$ value measured in calcite fluid inclusions reflects the $\mathrm{H}-\mathrm{O}$ isotopic composition of metallogenic hydrothermal solutions more accurately than $\delta \mathrm{D}$ measurements in quartz $[51,52]$. Therefore, previous researchers have generally chosen to use calcites to determine the $\mathrm{H}-\mathrm{O}$ isotopic composition of the metallogenic fluid; these results are shown in Table 2.

In the Huize deposit, the characteristics of sphalerites from different stages of metallogenesis are very distinct. Isotope exchange reactions do not happen between fluid 
TABLE 2: $\mathrm{H}-\mathrm{O}$ isotopic compositions of sphalerite, calcite, and barite in Huize $\mathrm{Pb}-\mathrm{Zn}$ deposit, SW China.

\begin{tabular}{|c|c|c|c|c|c|}
\hline Numbers & Positions & Objects & $\delta^{18} \mathrm{O}_{\mathrm{H} 2 \mathrm{O}} \% 0$ & $\delta \mathrm{D} \%$ o & Date source \\
\hline HZ911-10 & $1^{\#}$ orebody & Lumpy calcite & 8.6 & -59.8 & \multirow{16}{*}{$\mathrm{a}$} \\
\hline HZ911-15 & $1^{\#}$ orebody & Lumpy calcite & 8.8 & -52.4 & \\
\hline HZQ25 & $6^{\#}$ orebody & Lumpy calcite & 7.7 & -50.2 & \\
\hline HZQ40 & $6^{\#}$ orebody & Porphyritic calcite & 7.9 & -55.6 & \\
\hline HZQ47 & $6^{\#}$ orebody & Lumpy calcite & 7.7 & -57.9 & \\
\hline HZQ55 & $6^{\#}$ orebody & Vein calcite & 7.9 & -54.1 & \\
\hline HZQ66 & $6^{\#}$ orebody & Lumpy calcite & 8.3 & -53.9 & \\
\hline HZQ77 & $6^{\#}$ orebody & Vein calcite & 8.0 & -58.0 & \\
\hline HZQ85 & $6^{\#}$ orebody & Porphyritic calcite & 7.5 & -52.7 & \\
\hline HQ10-12 & $10^{\#}$ orebody & Lumpy calcite & 8.7 & -53.2 & \\
\hline HQ10-18 & $10^{\#}$ orebody & Lumpy calcite & 7.0 & -57.3 & \\
\hline HQ10-25 & $10^{\#}$ orebody & Porphyritic calcite & 8.1 & -53.0 & \\
\hline HQ10-5 & $10^{\#}$ orebody & Vein calcite & 7.4 & -52.8 & \\
\hline HQ8-115 & $8^{\#}$ orebody & Lumpy calcite & 7.2 & -55.2 & \\
\hline HQ8-143 & $8^{\#}$ orebody & Lumpy calcite & 7.8 & -54.1 & \\
\hline HQ8-98 & $8^{\#}$ orebody & Vein calcite & 8.0 & -54.3 & \\
\hline HQO-99-1 & Qilinchang & Calcite & 7.8 & -43.5 & \multirow{6}{*}{$\mathrm{b}$} \\
\hline HQO-109-4 & Qilinchang & Calcite & 10.1 & -54.8 & \\
\hline $1631-38$ & Qilinchang & Calcite & 7.8 & -48.0 & \\
\hline HQ-84 & Qilinchang & Calcite & 9.7 & -51.5 & \\
\hline HQ-109-4 & Qilinchang & Calcite & 7.6 & -43.5 & \\
\hline $1751-2$ & Qilinchang & Calcite & 7.7 & -55.4 & \\
\hline HW-2-3 & Qilinchang & Calcite & 7.1 & -55.8 & \multirow{6}{*}{ c } \\
\hline $38-3$ & Qilinchang & Calcite & 6.4 & -64.0 & \\
\hline Hui-6-10 & Qilinchang & Calcite & 7.1 & -75.0 & \\
\hline $13-61$ & Qilinchang & Calcite & 8.0 & -57.0 & \\
\hline $14-2-8$ & Qilinchang & Calcite & -2.1 & -66.0 & \\
\hline Hui-8 & Kuangshanchang & Barite & 7.8 & -86.0 & \\
\hline Z0807-1r & $15^{\#}$ stope of tunnel $1752 \mathrm{~m}$ in Kuangshanchang & 1st stage sphalerite & 28.0 & -52.0 & \multirow{9}{*}{$\mathrm{d}$} \\
\hline $\mathrm{Z} 0807-4 \mathrm{r}$ & $15^{\#}$ stope of tunnel $1752 \mathrm{~m}$ in Kuangshanchang & 3rd stage sphalerite & 5.5 & -50.0 & \\
\hline Z0807-5r & $15^{\#}$ stope of tunnel $1752 \mathrm{~m}$ in Kuangshanchang & 3rd stage sphalerite & 2.2 & -55.0 & \\
\hline Z0807-6r & $15^{\#}$ stope of tunnel $1752 \mathrm{~m}$ in Kuangshanchang & 1st stage sphalerite & 25.5 & -50.0 & \\
\hline Z0807-10r & $15^{\#}$ stope of tunnel $1752 \mathrm{~m}$ in Kuangshanchang & 2nd stage sphalerite & 17.1 & -27.0 & \\
\hline Z0807-11r & $15^{\#}$ stope of tunnel $1752 \mathrm{~m}$ in Kuangshanchang & 3rd stage sphalerite & 4.0 & -43.0 & \\
\hline $\mathrm{Z} 0807-12 \mathrm{r}$ & $15^{\#}$ stope of tunnel $1752 \mathrm{~m}$ in Kuangshanchang & 2nd stage sphalerite & 13.2 & -49.0 & \\
\hline Z0807-13r & $15^{\#}$ stope of tunnel $1752 \mathrm{~m}$ in Kuangshanchang & 2nd stage sphalerite & 12.2 & -57.0 & \\
\hline Z0807-17r & $15^{\#}$ stope of tunnel $1752 \mathrm{~m}$ in Kuangshanchang & 1st stage sphalerite & 28.9 & -51.0 & \\
\hline JS-11-1 & Qilinchang & Barite & -91.3 & 11.6 & \multirow{10}{*}{ e } \\
\hline JS-11-2 & Qilinchang & Barite & -85.5 & 9.9 & \\
\hline JS-11-3 & Qilinchang & Barite & -87.8 & 11.8 & \\
\hline JS-12-1 & Qilinchang & Barite & -77.4 & 11.8 & \\
\hline JS-12-3 & Qilinchang & Barite & -80.5 & 11.7 & \\
\hline JS-13-1 & Qilinchang & Barite & -79.8 & 12.4 & \\
\hline JS-40-3 & Kuangshangchang & Barite & -73.7 & 12.4 & \\
\hline JS-40-5 & Kuangshangchang & Barite & -63.9 & 13.7 & \\
\hline JS-41-1 & Kuangshangchang & Barite & -75.1 & 13.4 & \\
\hline$J S-42-2$ & Kuangshangchang & Barite & -61.7 & 13.4 & \\
\hline
\end{tabular}

a, b, c, d, and e: data from Li et al. [10], Han et al. [16], Liu and Lin [21], this paper, and Wang [47]. Different stages of sphalerite from the same ores can be separated based on textural and structural observations (Figures 3, 4, 6, and 8 ). 

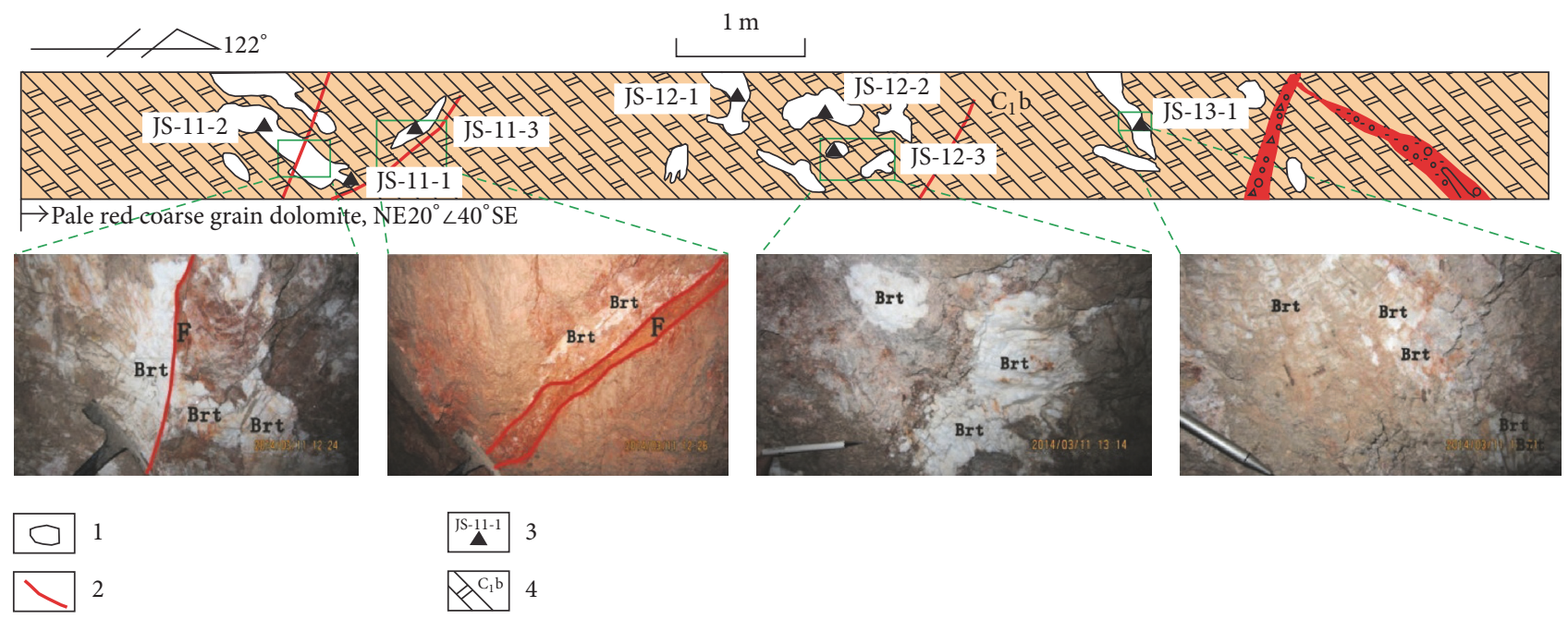

FIGURE 9: Documentation and sampling of 51\# transverse tunnel $1571 \mathrm{~m}$ of Zhujiayakou section in Qilinchang [47]. 1: barite; 2: fault; 3: sample location and sample number; 4: Lower Carboniferous Baizuo Fm. pale-red coarse-grained dolomite.

inclusions and minerals in later stages, and fluid inclusion petrography has shown that inclusions in sphalerite are mainly comprised of primary and pseudosecondary inclusions, with few secondary inclusions $[48,49]$. As the adsorbed water and the associated secondary inclusions have been removed from the sphalerite samples during the measurement process, the direct measurement of the $\mathrm{H}$ and O isotopic composition of sphalerite inclusions from different stages of metallogenesis is representative of the native isotopic composition of the metallogenic fluids, and these data also allow us to track the evolution of metallogenic fluids during different stages of metallogenesis.

Figure 11 shows the following.

(1) Similar to the $\mathrm{C}$ and $\mathrm{O}$ isotopic composition characteristics, the $\mathrm{H}-\mathrm{O}$ isotopic compositions of the Huize $\mathrm{Pb}-\mathrm{Zn}$ deposit are also relatively stable, with $\delta \mathrm{D}$ ranging within $-43.5 \%$ to $-66 \%$, with an average of $-56.3 \%$, and $\delta^{18} \mathrm{O}_{\mathrm{H} 2 \mathrm{O}}$ values ranging within $-2.05 \% 0-10.08 \%$, with an average of $7.55 \%$.

(2) The $\mathrm{H}-\mathrm{O}$ isotopic compositions of calcites from different orebodies, with different occurrences, do not differ significantly from one another. This characteristic reflects the presence of two different fluids within the metallogenic system, that is, a deeply sourced fluid, and a fluid sourced from atmospheric precipitation. Based on the geological conditions for metallogenesis and comparison between the $\mathrm{H}-\mathrm{O}$ isotopic compositions of the metallogenic fluid and those of orogenic mineral deposits [53-64], we deduced that the metallogenic fluid is a mix between deeply sourced fluids and basin brines.

However, it is worth noting that the $\delta^{18} \mathrm{O}_{\mathrm{H} 2 \mathrm{O}}$ value was calculated from the isotope equilibrium fractionation equation. During these calculations, the determination of the isotope equilibrium temperature significantly affects the $\delta^{18} \mathrm{O}_{\mathrm{H} 2 \mathrm{O}}$ value of the metallogenic fluid. Researchers in the past have chosen an average temperature of $200^{\circ} \mathrm{C}$ for this calculation, but this leads to an excessive aggregation of $\delta^{18} \mathrm{O}_{\mathrm{H} 2 \mathrm{O}}$ values in the distribution, as shown in the plot $(6 \%-10 \%)$. Apart from that, measurements of the temperature of the fluid inclusion are somewhat subjective and limited, and only statistical analysis of a large quantity of data can provide a reasonable approximation of reality. We collected all of the fluid inclusion temperature measurement data that are currently available for the Huize $\mathrm{Pb}-\mathrm{Zn}$ deposits $[48,49]$ (Figure 12); based on analysis of these data and our measurements, the temperatures of the metallogenic fluid in Stages I, II, III, and IV are $\left(190^{\circ} \mathrm{C}-205^{\circ} \mathrm{C}\right)$, $\left(170^{\circ} \mathrm{C}-190^{\circ} \mathrm{C}\right),\left(145^{\circ} \mathrm{C}-170^{\circ} \mathrm{C}\right)$, and $\left(130^{\circ} \mathrm{C}-150^{\circ} \mathrm{C}\right)$, respectively. Since calcites are products of Stages III and IV, $200^{\circ} \mathrm{C}$ is an overestimation of the average temperature. Studies have shown that the $\delta^{18} \mathrm{O}_{\mathrm{H} 2 \mathrm{O}}$ value and average temperature are proportionally related $[65,66]$; therefore, the projection of the actual $\delta^{18} \mathrm{O}_{\mathrm{H} 2 \mathrm{O}}$ values (for calcites) should be biased towards atmospheric precipitation, such that the distribution range of its $\mathrm{H}-\mathrm{O}$ isotopic compositions should be similar to or the same as that of Stage III sphalerite fluid inclusions.

(3) Among the nine sphalerite samples, except for Z080710r, which appears to be an outlier, the eight remaining samples are aggregated according to their stage of metallogenesis, in three clumps of 3,2, and 3, respectively. This indicates that the distribution of $\mathrm{H}$ and $\mathrm{O}$ isotopic compositions in the sphalerite fluid inclusions aggregate according to their stage of metallogenesis. Therefore, the results obtained here are representative of the native isotopic composition of metallogenic fluids during different stages of metallogenesis. The change in $\mathrm{H}$ isotopic compositions only varies slightly between Stages I, II, and III. In the figure, the range of distribution of samples from different stages contracts only slightly in the upwards direction. Changes in the isotopic composition of $\mathrm{O}$ are much more distinct, varying from $(25.5 \%$ o- $28.9 \% 0) \rightarrow(12.2 \% 0-17.1 \% 0) \rightarrow(2.2 \%$ o $-5.5 \% 0)$ from Stage I to Stage III. This indicates that the metallogenic fluid evolved from a deeply sourced fluid in Stage I to a fluid with 


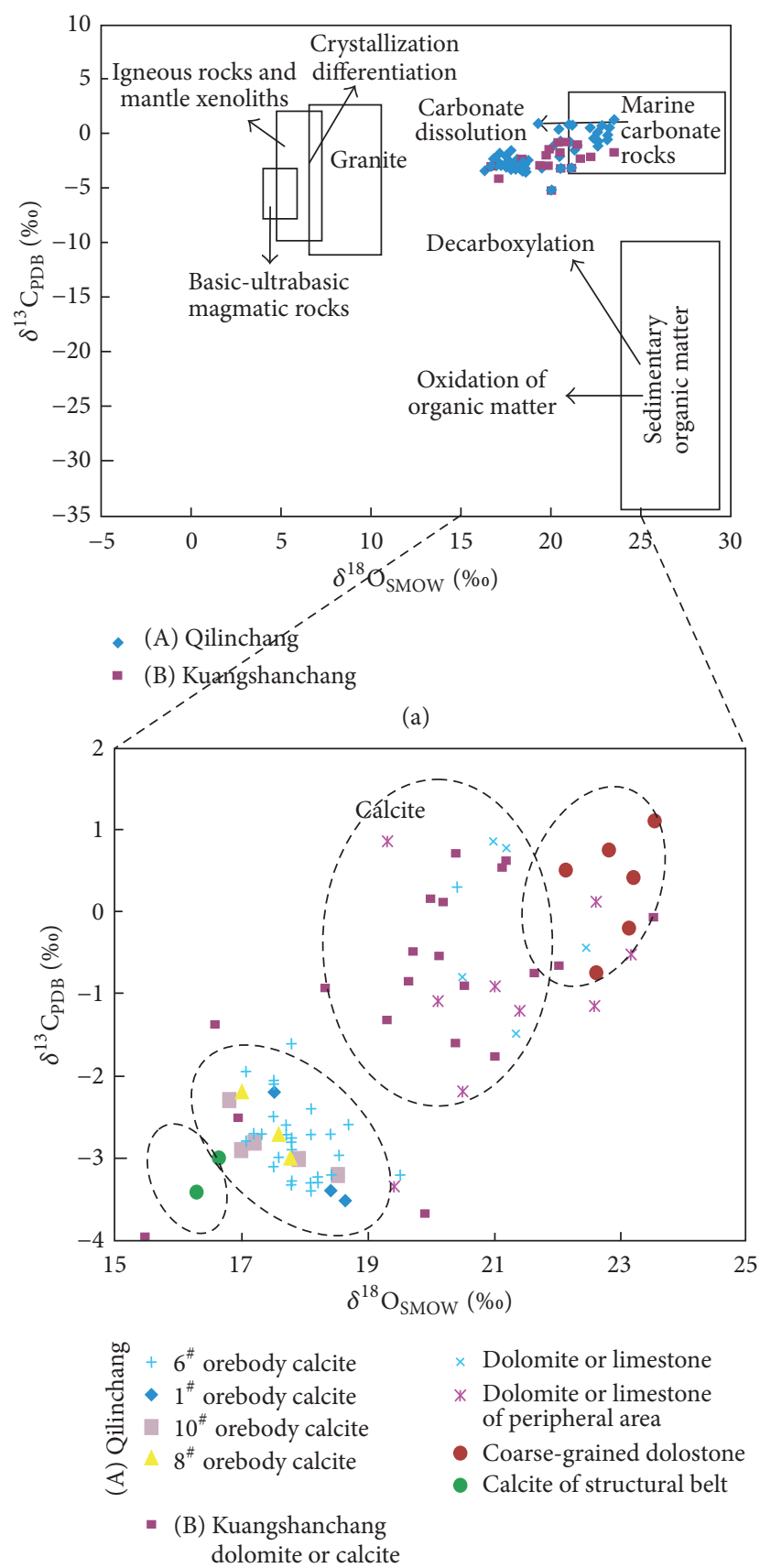

(b)

Figure 10: (a) C-O isotope composition diagram of Huize $\mathrm{Pb}-\mathrm{Zn}$ deposit. (b) C-O isotope composition diagram of different orebody and wall rocks in Huize $\mathrm{Pb}-\mathrm{Zn}$ deposit. Data sources: (A) previous data $[6,10,16,18,21]$; (B) this paper.

increasing levels of mixing from atmospheric precipitation in Stage III.

(4) The calculated $\delta^{18} \mathrm{O}_{\mathrm{H} 2 \mathrm{O}}$ values of the six Qilinchang barites range within $9.85 \% 0-12.36 \%$, with an average of $11.49 \%$. The $\delta \mathrm{D}$ values range within $-91.3 \%$ o to $-79.8 \%$, with an average of $-83.1 \%$. The $\delta^{18} \mathrm{O}_{\mathrm{H} 2 \mathrm{O}}$ values of the four Kuangshanchang barites range within $12.39 \% 0-13.69 \%$, with an average of $13.20 \%$; the $\delta \mathrm{D}$ values range within $-75.1 \%$ o to

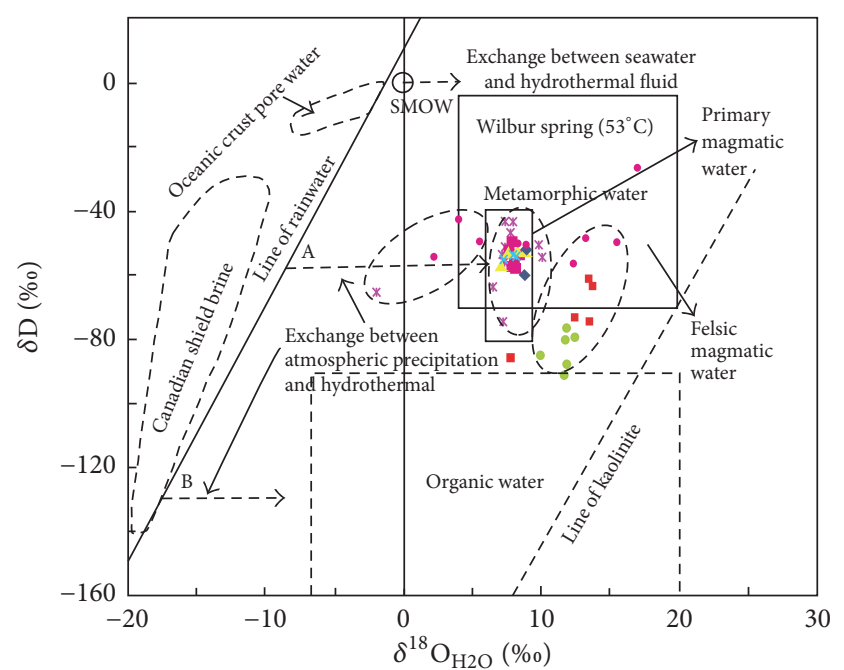
(a) Calcite
(b) Sphalerite
- $1^{\#}$ orebody
- $6^{\#}$ orebody
$10^{\#}$ orebody
$8^{\#}$ orebody
* Qilinchang
- Kuangshanchang
(c) Barite
- Kuangshanchang
- Qilinchang

Figure 11: Plot of $\delta \mathrm{D}$ versus $\delta^{18} \mathrm{O}_{\mathrm{H} 2 \mathrm{O}}$ values from Huize $\mathrm{Pb}-\mathrm{Zn}$ deposit. Data sources: (a) previous data $[10,16,21]$; (b) this paper; (c) Wang [47].

$-61.7 \%$, with an average of $-65.7 \%$. As a whole, the water in the inclusions within the Kuangshanchang barites is significantly more deuterium-enriched than the Qilinchang fluid inclusion water. The ranges of $\mathrm{H}-\mathrm{O}$ isotopic compositions of stage $I_{1}$ barites and stage $I_{2}$ sphalerites are essentially the same in this figure.

(5) The H-O isotopic composition of the fluid shows systematic changes from Stage I (barite, sphalerite) $\rightarrow$ Stage II (sphalerite) $\rightarrow$ Stage III (sphalerite, calcite) $\rightarrow$ Stage IV (calcite), as the metallogenic fluid gradually evolved from a deeply source fluid to a fluid that was mainly composed of atmospheric precipitation, which also reflects the gradual increase of basin brine mixing during metallogenesis (Figure 11).

\section{Identification of the Two Fluid Types}

We have previously studied the fluid inclusions of this deposit in detail $[48,49]$ and found that the homogenization temperature and salinity of sphalerite fluid inclusions in Kuangshanchang are the same as those of the Qilinchang deposit, which is consistent with the findings of Liu and Lin [21]; that is, the homogenization temperatures were distributed within $150^{\circ} \mathrm{C}-320^{\circ} \mathrm{C}$, and the decrepitation temperatures of the metallic minerals (pyrite, sphalerite, and galena) ranged within $140^{\circ} \mathrm{C}-480^{\circ} \mathrm{C}$.

The homogenization temperatures of sphalerite fluid inclusions in the Huize Kuangshanchang deposit covered a wide range, from $126^{\circ} \mathrm{C}$ to $280^{\circ} \mathrm{C}$ (Figures 12 and $13(\mathrm{~b})$ ), with a correspondingly high level of salinity, which ranged within 

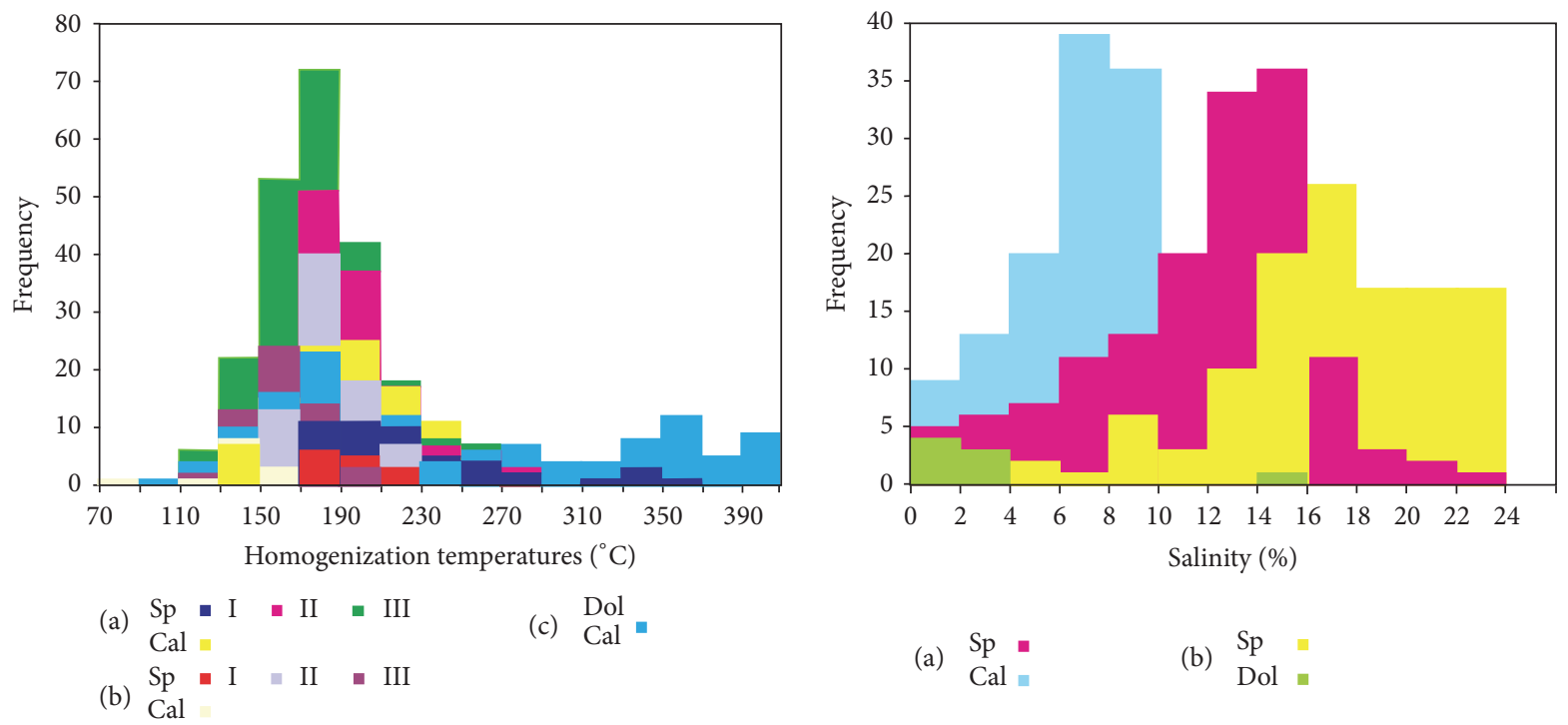

FIGURE 12: Distributions of homogenization temperatures and salinity in sphalerite and calcite (Zhang et al. [48]). Data sources: (a) Han et al. [49]; (b) Zhang et al. [48]; (c) Zhang [39]. There is no information from (c) in the salinity-frequency diagram because the data is incomplete; (a, c) Qilinchang deposit; (b) Kuangshanchang deposit.

$3.2 \%-22.7 \%$; the dolomite fluid inclusions had homogenization temperatures that ranged within $86^{\circ} \mathrm{C}-163^{\circ} \mathrm{C}$, with comparatively low levels of salinity, which ranged from $1.1 \%$ to $14.8 \%$.

The dolomite and sphalerite that correspond to each of the three stages of metallogenesis have fluid inclusions that display highly distinct distribution characteristics in their salinities and homogenization temperatures. From the first stage of metallogenesis (hydrothermal metallogenesis) to the alteration of adjacent rocks, the fluids evolved according to the following pattern: moderate-to-high temperatures and moderate-to-high salinity $\rightarrow$ moderate temperatures and moderate-to-high salinity $\rightarrow$ moderate-to-low temperatures and moderate-to-high salinity $\rightarrow$ moderate-to-low temperatures and low salinity. Patterns related to the mixing of moderate-to-high temperature-moderate-to-high salinity fluids with moderate temperature-moderate-to-high salinity fluids were also observed in the first stage of metallogenesis. The mixing of fluids with different levels of salinity under isothermal (moderate-to-low temperatures) conditions was observed for the $\mathrm{Sp}-\mathrm{Gn}$ and $\mathrm{Gn}-\mathrm{Sp}$ stages of metallogenesis (i.e., the primary stages of metallogenesis), while mixing between fluids with moderate-to-high levels of salinity with fluids of low salinity under moderate-to-low temperatures was observed in the alteration of adjacent rocks.

It is thus shown that a minimum of two fluids with different levels of salinity participated in hydrothermal metallogenesis. Hence, the mixing of fluids was likely the primary mechanism of mineral precipitation in the Huize deposit. This is consistent with the immiscibility represented by the coexistence of purely gaseous and gas-liquid inclusions, which were observed in fluid inclusion studies [48, 49, 67].

The $\mathrm{C}-\mathrm{O}$ and $\mathrm{H}-\mathrm{O}$ isotopic compositions and the homogenization temperature-salinity distribution map obtained from the results of previous fluid inclusion studies
(Figure 13) are both indicative of fluid mixing during metallogenesis. In particular, the $\mathrm{H}-\mathrm{O}$ isotopic composition of stage $\mathrm{I}_{1}$ barites and the $\mathrm{C}-\mathrm{O}$ isotopic compositions of calcites from the NE-trending tectonic belt show that the metallogenic Fluid $\mathrm{A}$ of the Huize $\mathrm{Pb}-\mathrm{Zn}$ deposit originates from deep-seated sources and is rich in lighter $\mathrm{C}$ and $\mathrm{O}$ isotopes. The $\mathrm{C}-\mathrm{O}$ isotopic compositions of wall rocks in the periphery of the mining area and the $\mathrm{H}-\mathrm{O}$ isotopic compositions of early-stage sphalerites indicate that Fluid B comprises subsurface brines formed by atmospheric precipitation that leached adjacent carbonate rocks and extracted reduced sulfurs from various strata. This fluid has heavier $\mathrm{C}-\mathrm{O}$ and $\mathrm{H}-\mathrm{O}$ isotopic compositions than Fluid A. When fluids A and B were mixed, their isotopes were exchanged, which led to the final mixed fluid having $\mathrm{C}-\mathrm{O}$ and $\mathrm{H}-\mathrm{O}$ compositions that are in between those of the two metallogenic fluids.

Based on the geological characteristics of the deposit and the findings of fluid inclusion studies, the high-temperature barites that occur within the fracture zone and side fractures were precipitated from Fluid A because of high oxygen fugacity and oversaturation; hence, the geological body that corresponds to Fluid A is high-temperature barite. In contrast, Fluid B is composed of stratigraphic brine formed by atmospheric precipitation that leached adjacent carbonates and extracted reduced sulfides from the strata, and its corresponding geological bodies are carbonate strata, as well as pyrite and gypsum strata formed during sedimentation and diagenesis. The mixing of fluids $\mathrm{A}$ and $\mathrm{B}$ caused the precipitation of sulfides; hence, the geological bodies that correspond to the mixed fluid are zinc and lead sulfide ores. Information on the two types of fluids and the mixed fluid is shown in Table 3.

Based on the above characteristics, we hypothesize that the metallogenesis of the Huize $\mathrm{Pb}-\mathrm{Zn}$ deposit occurred 


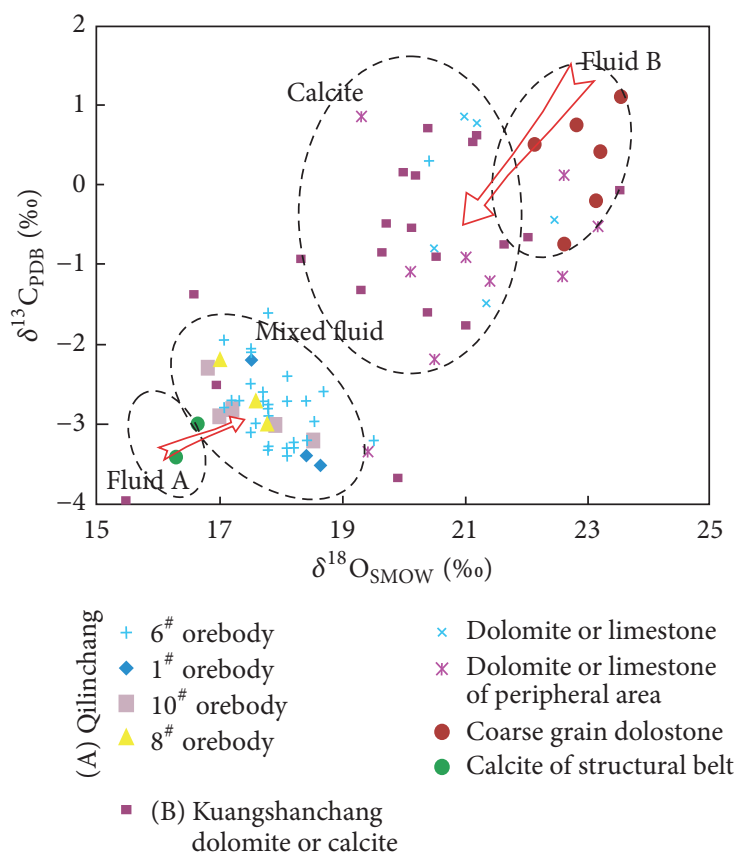

(a)

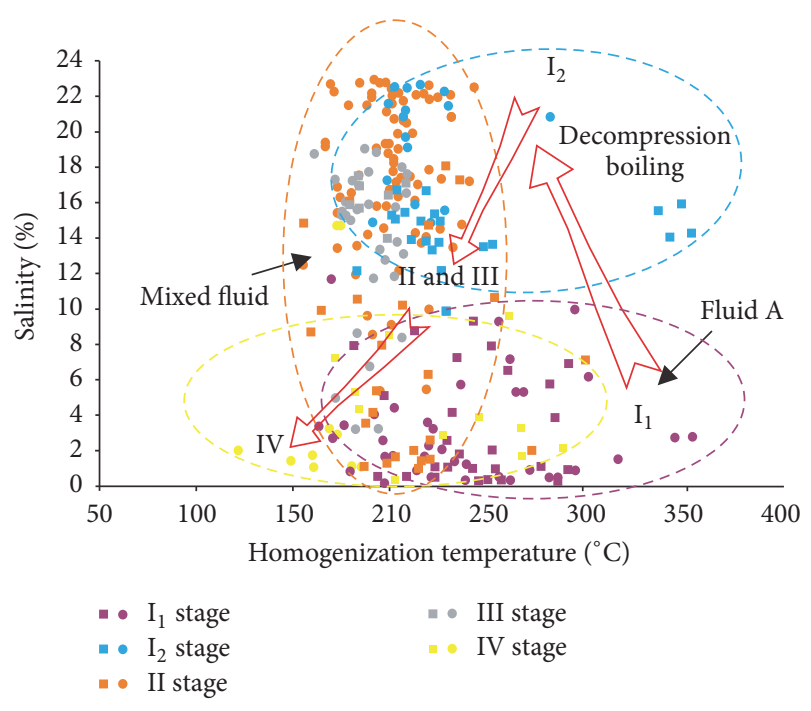

(b)

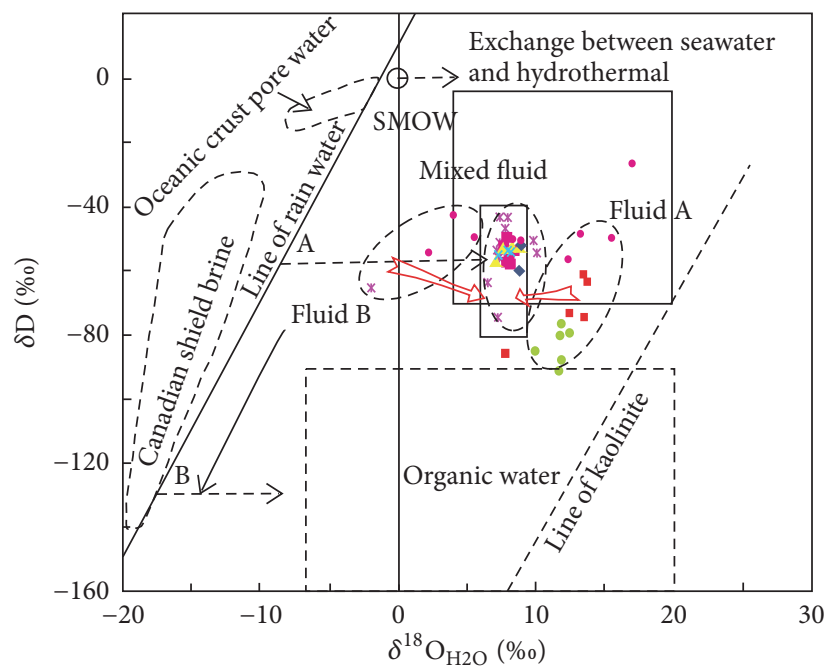
(A) Calcite
- $1^{\#}$ orebody
(B) Sphalerite
- $6^{\#}$ orebody
- Kuangshanchang
$410^{\#}$ orebody
$\times 8^{\#}$ orebody
* Qilinchang
(C) Barite
- Kuangshanchang
- Qilinchang

(c)

Figure 13: Identification diagram for the two fluid types in the Huize $\mathrm{Pb}-\mathrm{Zn}$ deposit. (a) $\mathrm{H}-\mathrm{O}$ isotope composition diagram. (b) Homogenization temperature-salinity diagram. (c) C-O isotope composition diagram.

according to the following process: tectonic activity during the Indosinian caused large-scale upward movement of deepseated fluids; as these fluids flowed through the carbonate strata, they exchanged $\mathrm{C}$ and $\mathrm{H}$ isotopes with these strata and extracted the metallic elements, thus forming the metal-rich, acidic, moderate-to-high temperature and low salinity Fluid
A, whose lead and zinc contents mainly exist as $\mathrm{Pb}-\mathrm{Zn}-\mathrm{Cl}$ compounds. Furthermore, as the carbonate strata provided sufficient $\mathrm{CO}_{3}{ }^{2-}$ and $\mathrm{HCO}_{3}{ }^{-}$to buffer the $\mathrm{pH}$ of the metallogenic fluid, $\mathrm{Pb}-\mathrm{Zn}-\mathrm{Cl}$ compounds were stably maintained within the fluid (because of its acidity), which prevented the precipitation of lead and zinc sulfides from the fluid [48]. As 
TABle 3: Characteristics of the two fluid types in the Huize Pb-Zn deposit, SW China.

\begin{tabular}{|c|c|c|c|}
\hline & Fluid A & Fluid B & Mixed fluid \\
\hline Source & Deep & $\begin{array}{c}\text { Brine water from atmospheric } \\
\text { Precipitation leaching the host rock }\end{array}$ & Mixed $A$ and $B$ \\
\hline Salinity & $<10 \mathrm{wt} \% \mathrm{NaCl}$ & $>20 \mathrm{wt} \% \mathrm{NaCl}$ & $2-23 \mathrm{wt} \% \mathrm{NaCl}$ \\
\hline $\mathrm{pH}$ & $<3.6$ & $>6$ & $5-8$ \\
\hline $\mathrm{CO}_{2}$ & Abundant & Abundant & First increased, then decreased \\
\hline $\mathrm{SO}_{4}{ }^{2-}$ & 70 ppm & No & No \\
\hline $\mathrm{HS}^{-}$ & No & Sulfate strata reduction & Precipitated as sulfides \\
\hline $\mathrm{Pb}, \mathrm{Zn}$ complex & Cl-complex & Little or none & Sulfide precipitation \\
\hline$\delta^{13} \mathrm{C} \%$ & $-3 \% 0<\delta^{13} \mathrm{C} \% 0<-4 \%$ & $-2 \% 0<\delta^{13} \mathrm{C} \%$ < $1 \%$ o & $-4 \% o<\delta^{13} \mathrm{C} \% 0<1 \%$ \\
\hline$\delta \mathrm{D} \%$ & $-92 \%$ o $<\delta \mathrm{D}_{0}<-50 \%$ & $-66 \% 0<\delta \mathrm{D} \%$ o $<-43 \%$ o & $-75 \% 0<\delta \mathrm{D} \%$ o $<-43 \%$ \\
\hline$\delta^{18} \mathrm{O} \%$ & $10 \%$ < $\delta^{18} \mathrm{O} \% 0<17 \%$ & $2 \% o<\delta^{18} \mathrm{O} \%$ < $<24 \%$ & $7 \% o<\delta^{18} \mathrm{O} \%$ o $<22 \%$ \\
\hline Property & Acid oxidation & Neutral-alkaline and reducing & Near neutral \\
\hline $\begin{array}{l}\text { Corresponding major } \\
\text { minerals }\end{array}$ & Barite and sphalerite in I stage & Calcite in IV stage & Galena, sphalerite in II and III stages \\
\hline
\end{tabular}

the metallogenic fluid moved towards ore-containing strata along large ore-inducing tectonic structures, decompression boiling occurred when the fluids penetrated the NE-trending interstratum reverse shear fracture $[48,49]$, causing the metallogenic substances to become even more concentrated and enriched, which led to the partial precipitation of sphalerites and galena. Sulfides precipitated in this manner have a high temperature, $\sim 300^{\circ} \mathrm{C}$. This fluid then mixed with Fluid B, causing its temperature to decrease and its $\mathrm{pH}$ to increase, resulting in the precipitation of large quantities of sulfides. The sulfides precipitated in this stage have a lower temperature, between $170^{\circ} \mathrm{C}$ and $230^{\circ} \mathrm{C}$, and overlap with the sulfides formed during the boiling of the fluid, thus forming the primary orebodies.

\section{Conclusion}

Based on $\mathrm{C}-\mathrm{O}$ and $\mathrm{H}-\mathrm{O}$ isotopic compositions and the findings of fluid inclusion studies, it was found that there are two metallogenic fluids present in the Huize $\mathrm{Pb}-\mathrm{Zn}$ deposit: Fluid A and Fluid B. Fluid A originates from deep-seated fluid sources and is enriched in lighter $\mathrm{C}$ and $\mathrm{O}$ isotopes, whereas Fluid B is composed of subsurface brine formed by atmospheric precipitation that leached carbonate wall rocks and extracted thermochemically reduced sulfurs from stratigraphic pyrites and carbonates (gypsum). Fluid B is characterized by heavier $\mathrm{C}-\mathrm{O}$ and $\mathrm{H}-\mathrm{O}$ isotopic compositions than Fluid A. These fluids mixed during metallogenesis, which resulted in the exchange of isotopes between the two fluids. Consequently, the final mixed fluid has $\mathrm{C}-\mathrm{O}$ and $\mathrm{H}-\mathrm{O}$ isotopic compositions that lie between those of the two metallogenic fluids.

Therefore, the metallogenesis of the Huize $\mathrm{Pb}-\mathrm{Zn}$ deposit can be summarized as follows. During tectonic activity in the Indosinian Period, deep-seated fluids moved upwards on a large scale through carbonate strata of various ages. The fluids extracted the metallic elements of these strata to form a metal-rich metallogenic fluid, which underwent gas-liquid separation under the process of decompression boiling in structurally favorable spaces. After further enrichment and concentration and precipitation of some of the higher-grade ores, this fluid then mixed with Fluid B and continued to precipitate sulfides within the Huize $\mathrm{Pb}-\mathrm{Zn}$ deposit.

\section{Conflicts of Interest}

The authors declare that they have no conflicts of interest.

\section{Acknowledgments}

This study was supported jointly by the National Natural Science Foundation of China (nos. 41572060 and U1133602), projects of YM Lab (2011) and Innovation Team of Yunnan Province and KMUST (2008 and 2012), and Yunnan and Kunming University of Science and Technology Postdoctoral Sustentation Fund.

\section{References}

[1] Z. X. Dai, "The distributions, types and rules of exploration of lead and zinc all over the world," World Nonferrous Metals, vol. 3, pp. 15-23, 2005.

[2] J. R. Xie, A Discussion on the Deposits Classify, Science Press, Beijing, China, 1st edition, 1963.

[3] W. J. Zhang, "A preliminary discussion on the sedimentary origin and metallogenic rule of $\mathrm{Pb}-\mathrm{Zn}$ deposits in Northeastern Yunnan," Geology and Exploration, vol. 7, pp. 11-16, 1984.

[4] G. Z. Tu, Geochemical of Strata Bound Ore Deposits in China: First Volume, Science Press, Beijing, China, 1st edition, 1984.

[5] W. Liao, "The features of $\mathrm{S}$ and $\mathrm{Pb}$ isotope and the discussion on model of metallogenic in Eastern of Yunnan and Western of Guizhou," Geology Deposit, vol. 1, pp. 1-6, 1984.

[6] C. X. Zhou, The Source of Mineralizing Metals, Geochemical Characterization of Ore Forming Solution, and Metallogenetic Mechanism of Qilingchang $\mathrm{Pb}-\mathrm{Zn}$ Deposit, Northeastern Yunnan Province, China, [M.S. thesis], The Institute of Geochemistry, Chinese Academy of Sciences, 1996. 
[7] C. X. Zhou, "The source of mineralizing metals, geochemical characterization of ore-forming solution, and metallogenetic mechanism of qilingchang $\mathrm{Pb}-\mathrm{Zn}$ deposit, Northeastern Yunnan province, China," Bulletin of Mineralogy, Petrology and Geochemistry, vol. 17, no. 1, pp. 34-36, 1998.

[8] Z. L. Huang, J. Chen, and R. S. Han, Geochemistry and Ore Genesis of Huize Super-Large Lead-Zinc Deposit, Yunnan Province, Concurrently Discuss the Relationship Between Emeishan Basalt and Lead-Zinc Deposits, Geological Publishing House, Beijing, China, 1st edition, 2004.

[9] W. B. Li, Z. L. Huang, and Y. X. Wang, "Age of the giant huize $\mathrm{Zn}-\mathrm{Pb}$ deposits determined by $\mathrm{Sm}-\mathrm{Nd}$ dating of hydrothermal calcite," Georgica Review, vol. 50, no. 2, pp. 189-195, 2004.

[10] W. Li, Z. Huang, and G. Zhang, "Sources of the ore metals of the huize ore field in yunnan province: constraints from $\mathrm{Pb}, \mathrm{S}, \mathrm{C}, \mathrm{H}$, $\mathrm{O}$ and Sr isotope geochemistry," Acta Petrologica Sinica, vol. 22, no. 10, pp. 2567-2580, 2006.

[11] Z. B. Zhang, C. Y. Li, G. Z. Tu, B. Xia, and Z. Q. Wei, "Geotectonic evolution background and ore forming process of $\mathrm{Pb}$-An deposits in Chuan-Dian-Qian Area of Southwest China," Geotectonica et Metallogenia, vol. 30, no. 3, pp. 343-354, 2006.

[12] R. S. Han, C. Q. Liu, Z. L. Huang et al., "Sources of ore-forming fluid in huize $\mathrm{Zn}-\mathrm{Pb}-(\mathrm{Ag}-\mathrm{Ge})$ district, Yunnan, China," Acta Geologica Sinica, vol. 78, no. 2, pp. 583-591, 2004.

[13] R.-S. Han, C.-Q. Liu, Z.-L. Huang et al., "Geological features and origin of the Huize carbonate-hosted $\mathrm{Zn}-\mathrm{Pb}-(\mathrm{Ag})$ District, Yunnan, South China," Ore Geology Reviews, vol. 31, no. 1-4, pp. 360-383, 2007.

[14] H. Run-sheng, L. Cong-Qiang, E. J. M. Carranza et al., "REE geochemistry of altered tectonites in the Huize base-metal district, Yunnan, China," Geochemistry: Exploration, Environment, Analysis, vol. 12, no. 2, pp. 127-146, 2012.

[15] R. S. Han, C. Q. Liu, Z. L. Huang, J. Chen, D. Y. Ma, and Y. Li, "Study on the metallogenic model of the huize $\mathrm{Pb}-\mathrm{Zn}$ deposit in Yunnan Province," Acta Mineralogica Sinica, vol. 21, no. 4, pp. 674-680, 2001.

[16] R. S. Han, J. Chen, Z. L. Huang et al., ynamics of Tectonic Ore-forming Process and Localization-Prognosis of Concealed Orebodies-As Exemplified by the Huize Super-large $\mathrm{Zn}-\mathrm{Pb}$ - $(\mathrm{Ag}$ Ge) District, Yunnan, Beijing Science Press, Beijing, China, 1st edition, 2006.

[17] R. Han, W. Li, W. Qiu, T. Ren, and F. Wang, "Typical geological features of rich $\mathrm{Zn}-\mathrm{Pb}-(\mathrm{Ge}-\mathrm{Ag})$ deposits in Northeastern Yunnan, China," Acta Geologica Sinica, vol. 88, no. s2, pp. 160-162, 2014.

[18] S. J. Chen, "A Discussion on the sedimentary origin of PbZn deposits in Western Guizhou and Northeastern Yunnan," Guizhou Geology, vol. 8, no. 3, pp. 35-39, 1984.

[19] J. Chen Jin, "A discussion on the genesis and metallogenic model of the qilinchang $\mathrm{Pb}-\mathrm{Zn}$ sulfide deposit," Non-Ferrous Mineral Resources and Exploration, vol. 2, pp. 85-90, 1993.

[20] Z. Zhao, "Metallogenic model of Pb-Zn deposits in Northeastern Yunnan," Yunnan Geology, vol. 14, no. 4, pp. 350-354, 1985.

[21] H. C. Liu and W. D. Lin, Metallogenic Rules of $\mathrm{Zn}-\mathrm{Pb}-(\mathrm{Ag})$ Deposits in Northeastern Yunnan, Yunnan University Publishing House, Kunming, China, 1st edition, 1999.

[22] C. Q. Zhang, he Genetic Model of Mississippi Valley-Type Deposits in the Boundary Area of Sichuan, Yunnan and Guizhou Provinces, China, [M.S. thesis], Chinese Academy of Geological Sciences, 2008.
[23] R. S. Han, Y. Z. Hu, X. K. Wang et al., "Mineralization model of rich $\mathrm{Ge}$-Ag-bearing $\mathrm{Zn}$-Pb polymetallic deposit concentrated district in Northeastern Yunnan, China," Acta Geologica Sinica, vol. 86, no. 2, pp. 280-293, 2012.

[24] R. Han, F. Wang, Y. Hu et al., "Metallogenic tectonic dynamics and chronology constrains on the huize-type (HZT) germanium-rich silver-zinc-lead deposits," Geotectonica et Metallogenia, vol. 38, no. 4, pp. 758-771, 2014.

[25] D. R. Gao, "The ore -forming geological condition and the ore prospecting direction of huize lead zinc deposit," Journal of Kunming University of Science and Technology, vol. 25, no. 4, pp. 19-24, 2000.

[26] J. Chen, D. R. Gao, and D. C. Wu, The Report of the Geology Exploration of 8\# Ore Body in Qilinchang Pb-Zn Deposit, Huize, Yunnan, Huize Lead-Zinc Deposit, Huize, China, 2001.

[27] R. S. Han, H. J. Zou, B. Hu, Y. Z. Hu, and C. D. Xue, "Features of fluid inclusions and sources of ore-forming fluid in the maoping carbonate-hosted $\mathrm{Zn}-\mathrm{Pb}-(\mathrm{Ag}-\mathrm{Ge})$ deposit, Yunnan, China," Acta Petrological Sinica, vol. 23, no. 09, pp. 2109-2118, 2007.

[28] C. Q. Zhang, J. W. Mao, S. P. Wu et al., "Distribution, characteristics and genesis of mississippi valley-type lead-zinc deposits in Sichuan-Yunnan-Guizhou area," Mineral Deposits, vol. 24, no. 3, pp. 336-348, 2005.

[29] C. Q. Zhang, Z. Y. Rui, Y. C. Chen, D. H. Wang, Z. H. Chen, and D. B. Lou, "The main successive strategic bases of resources for $\mathrm{Pb}-\mathrm{Zn}$ deposits in China," Geology in China, vol. 40, no. 1, pp. 248-272, 2013.

[30] J. Z. Wang, C. Y. Li, Z. Q. Li, and J. J. Liu, “The geological setting, characters and origin of mississippi valley-type $\mathrm{Pb}-\mathrm{Zn}$ deposits in Sichuan and Yunnan provinces," Geology-Geochemistry, vol. 29, no. 2, pp. 41-45, 2001.

[31] J. Z. Wang, C. Y. Li, Z. Q. Li, B. H Li, and W. Z. Liu, “The comparison of mississippi valley-type lead-zinc deposits in Southwest of China and in mid-continent of United States," Bulletin of Mineralogy, Petrology and Geochemistry, vol. 21, pp. 127-132, 2002.

[32] G.-Z. Tu, "Two unique mineralization areas in Southwest China," Bulletin of Mineralogy Petrology and Geochemistry, vol. 21, no. 1, pp. 1-2, 2002.

[33] Z. L. Huang, J. Chen, R. S. Han et al., "REE Geochemistry of calcite- A Gangue mineral in the Huize ore deposit, Yunnan," Acta Mineralogica Sinica, vol. 31, no. 4, pp. 659-666, 2001.

[34] Z. L. Huang, W. B. Li, J. Chen et al., "Carbon and oxygen isotope constraints on mantle fluid involvement in the mineralization of the Huize super-large $\mathrm{Pb}-\mathrm{Zn}$ deposits, Yunnan Province, China," Journal of Geochemical Exploration, vol. 78-79, pp. 637642, 2003.

[35] Z. Huang, X. Li, M. Zhou, W. Li, and Z. Jin, "REE and C-O Isotopic geochemistry of calcites from the world-class huize $\mathrm{Pb}$ Zn deposits, Yunnan, China: implications for the ore genesis," Acta Geologica Sinica, vol. 84, no. 3, pp. 597-613, 2010.

[36] D. F. Luo, Z. L. Huang, F. Wang, J. X. Zhou, and X. B. Li, "Mechanism of transportation and precipitation of mineralization elements in the huize super-large $\mathrm{Pb}-\mathrm{Zn}$ deposit, Yunnan Province, China," Acta Mineralogica Sinica, vol. 32, no. 2, pp. 288-293, 2012.

[37] Z. L. Zhang, Z. L. Huang, B. Rao, T. Guan, and Z. F. Yan, "Study on the ore forming fluid characteristics of huize $\mathrm{Pb}-\mathrm{Zn}$ ore deposits," Geological Prospecting Review, vol. 20, no. 2, pp. 115121, 2005. 
[38] Z. L. Zhang, Z. L. Huang, B. Rao, T. Guan, and Z. F. Yan, "Concentration mechanism of ore-forming fluid in huize leadzinc deposits, Yunnan province," Earth Science-Journal of China University of Geosciences, vol. 30, no. 4, pp. 443-450, 2005.

[39] Z. L. Zhang, Feature and Sources of Ore-Forming Fluid in the Huize Lead-Zinc Ore Deposit, Yunnan Province, China: Evidence from Fluid Inclusions and Water-Rock Reaction Experiments, [M.S. thesis], The Institute of Geochemistry, Chinese Academy of Sciences, 2006.

[40] Z. L. Zhang, Z. L. Huang, B. Rao, T. Guan, and Z. F. Yan, "Are lead sulphides and zinc sulphides of lead-zinc ore deposits precipitated from acidic solutions? a discussion on the oreforming fluid of Huize lead-zinc ore deposit, Yunnan province," Acta Mineralogica Sinica, vol. 26, no. 01, pp. 53-58, 2006.

[41] X. R. Yan, The Ore-Forming Pattern and The Ore-Forming Prognosis of the Huize Lead And Zinc Deposit, [M.S. thesis], Kunming University of Science and Technology, 2007.

[42] K. H. Zhong, W. Liao, M. Y. Song, and Y. Q. Zhang, "Discussion on sulfur isotope of Huize $\mathrm{Pb}-\mathrm{Zn}$ deposit in Yunnan, China," Journal of Chengdu University of Technology (Science \& Technology Edition), vol. 40, no. 2, pp. 130-138, 2013.

[43] Y. Zhang, R. S. Han, and P. T. Wei, "Research overview on the migration and precipitation mechanisms of lead and zinc in oreforming fluid system for carbonate-hosted lead-zinc deposits," Geological Review, vol. 62, no. 1, pp. 187-201, 2016.

[44] W. H. Hu and Z. H. Feng, "Quality evaluation of deep rock mass in the Huize lead zinc mine," Mining Technology, vol. 9, no. 01, pp. 43-47, 2009.

[45] Z. C. Liu, F. Y. Li, K. H. Zhong, W. Li, and S. Y. Wen, The Tectonic and Metallogenic of the Western Margin of the Yangtze Platform and Its Adjacent Area, Press of University of Electronic Science and Technology of Beijing, 1996.

[46] B. L. Wang, S. K. Lv, and J. G. Hu Jugui, "A tentative description of the Chuan-dian-qian rhombic massif," Yunnan Geology, vol. 23, no. 2, pp. 140-153, 2004.

[47] L. Wang, The Research on Original of Ore-Forming Fluid and Matter in the Huize Lead-Zinc Deposit, Kunming University of Science and Technology, 2016.

[48] Y. Zhang, R. S. Han, P. T. Wei, and W. L. Qiu, "Fluid inclusion features and physical and chemical conditions of the ore-forming fluid in kuangshanchang $\mathrm{Pb}-\mathrm{Zn}$ deposit, Huize, Yunnan," Journal of Jilin University (Earth Science Edition), vol. 47, no. 3, pp. 719-733, 2017.

[49] R. Han, B. Li, P. Ni, W. Qiu, X. Wang, and T. Wang, "Infrared micro-thermometry of fluid inclusions in sphalerite and geological significance of Huize super-large $\mathrm{Zn}-\mathrm{Pb}-(\mathrm{Ge}-$ Ag) deposit, Yunnan province," Journal of Jilin University (Earth Science Edition), vol. 46, no. 1, pp. 91-104, 2016.

[50] Y. F. Zheng and J. F. Cheng, Stable Isotope Geochemistry, Scientific Publishing House, Beijing, China, 2000.

[51] C. Y. Li, Y. P. Liu, Q. Zhang, D. H. Pi, W. L. Zhang, and J. Chen, "Discovery of antimony and distribution characteristics of associated elements in Huize $\mathrm{Pb}-\mathrm{Zn}$ deposit," Mineral Deposits, vol. 24, no. 1, pp. 52-60, 2005.

[52] P. F. Dennis, P. J. Rowe, and T. C. Atkinson, "The recovery and isotopic measurement of water from fluid inclusions in speleothems," Geochimica et Cosmochimica Acta, vol. 65, no. 6, pp. 871-884, 2001.

[53] R. J. Goldfarb, R. J. Newberry, W. J. Pickthorn, and C. A. Gent, "Oxygen, hydrogen, and sulfur isotope studies in the Juneau gold belt, southeastern Alaska: constraints on the origin of hydrothermal fluids," Economic Geology, vol. 86, no. 1, pp. 6680, 1991.

[54] R. J. Goldfarb, L. D. Miller, D. L. Leach, and L. W. Snee, "Gold deposits in metamorphic rocks of Alaska," Economic Geology Monograph, vol. 9, pp. 151-190, 1997.

[55] D. J. Kontak and R. Kerrich, "Geological and geochemical studies of a metaturbidite-hosted lode gold deposit: the Beaver Dam deposit, Nova Scotia: II. Isotopic studies," Economic Geology, vol. 90, no. 4, pp. 885-901, 1995.

[56] T. Oberthür, A. S. Mumm, U. Vetter, K. Simon, and J. A. Amanor, "Gold mineralization in the Ashanti belt of Ghana: genetic constraints of the stable isotope geochemistry," Economic Geology, vol. 91, no. 2, pp. 289-301, 1996.

[57] S. M. Ivanov, K. M. Ansdell, and D. L. Melrose, "Ore texture and stable isotope constraints on ore deposition mechanisms at the Kumtor lode gold deposit," in Gold in 2000: Luke Tahoe-Reno, Nevada, November 10-11, 2000, Centre for Global Metallogeny, University of Western Australia, Extended Abstract Volume, L. A. Bucci and J. L. Mair, Eds., pp. 47-52, 2000.

[58] R. Kerrich, The Stable Isotope Geochemistry of Au-Ag Vein Deposits in Metamorphic Rocks, Mineralogical Association of Canada Short Course Handbook, 1987.

[59] S. D. Golding, N. J. McNaughton, M. E. Barley et al., "Archean carbon and oxygen reservoirs: Their significances for fluid sources and circulation paths for Archean mesothermal gold deposits of the Norseman-Wiluna belt, Western Australia," Economic Geology Monograph, vol. 6, pp. 376-388, 1989.

[60] C. E. J. De Ronde, E. T. C. Spooner, M. J. De Wit, and C. J. Bray, "Shear zone-related, Au quartz vein deposits in the Barberton Greenstone Belt, South Africa: field and petrographic characteristics, fluid properties, and light stable isotope geochemistry," Economic Geology, vol. 87, no. 2, pp. 366-402, 1992.

[61] T. C. McCuaig and R. Kerrich, "P-T-t-deformation-fluid characteristics of lode gold deposits: evidence from alteration systematics," Ore Geology Reviews, vol. 12, no. 6, pp. 381-453, 1998.

[62] Y. Jia, X. Li, and R. Kerrich, "Stable isotope (O, H, S, C, and $\mathrm{N})$ systematics of quartz vein systems in the turbidite-hosted Central and North Deborah gold deposits of the Bendigo gold field, Central Victoria, Australia: Constraints on the origin of ore-forming fluids," Economic Geology, vol. 96, no. 4, pp. 705721, 2001.

[63] R. J. Goldfarb, R. Ayuso, M. L. Miller et al., “The late cretaceous Donlin Creek gold deposit, Southwestern Alaska: Controls on epizonal ore formation," Economic Geology, vol. 99, no. 4, pp. 643-671, 2004.

[64] K. Faure, " $\delta \mathrm{D}$ values of fluid inclusion water in quartz and calcite ejecta from active geothermal systems: Do values reflect those of original hydrothermal water?" Economic Geology, vol. 98, no. 3, pp. 657-660, 2003.

[65] L. Q. Yang, J. Deng, J. Zhang, C. Y. Guo, B. F. Gao, and Q. J Gong, "Decrepitation thermometry and compositions of fluid inclusions of the Damoqujia gold deposit, Jiaodong gold province, China: implications for metallogeny and exploration," Journal of Earth Science, vol. 19, no. 4, pp. 378-390, 2008.

[66] C. Y. Guo, L. Q. Yang, J. Zhang, B. F. Gao, Q. F. Wang, and H. J. Yu, "Ore fluid chemical evolution and stable isotope composition of Damo Qujia gold deposit in Shandong province," Mineralogy and Petrology, vol. 28, no. 3, pp. 51-56, 2008.

[67] H. Z. Lu, H. R. Fan, and P. Ni, Fluid Inclusions, Science Press, Beijing, China, 1st edition, 2004. 

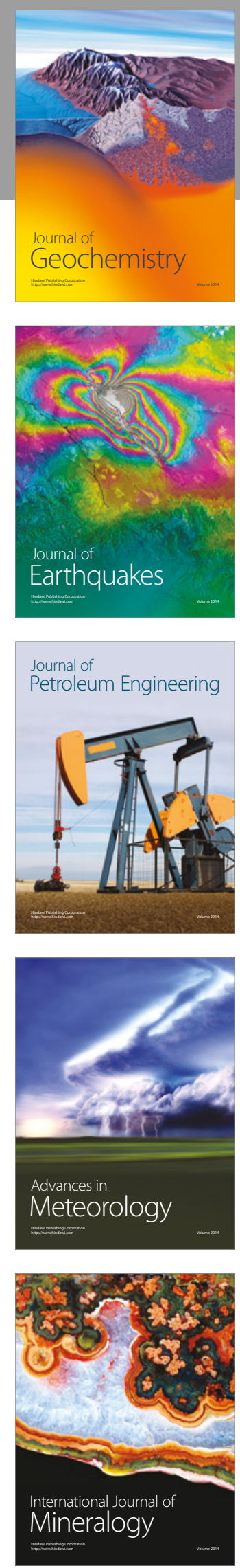
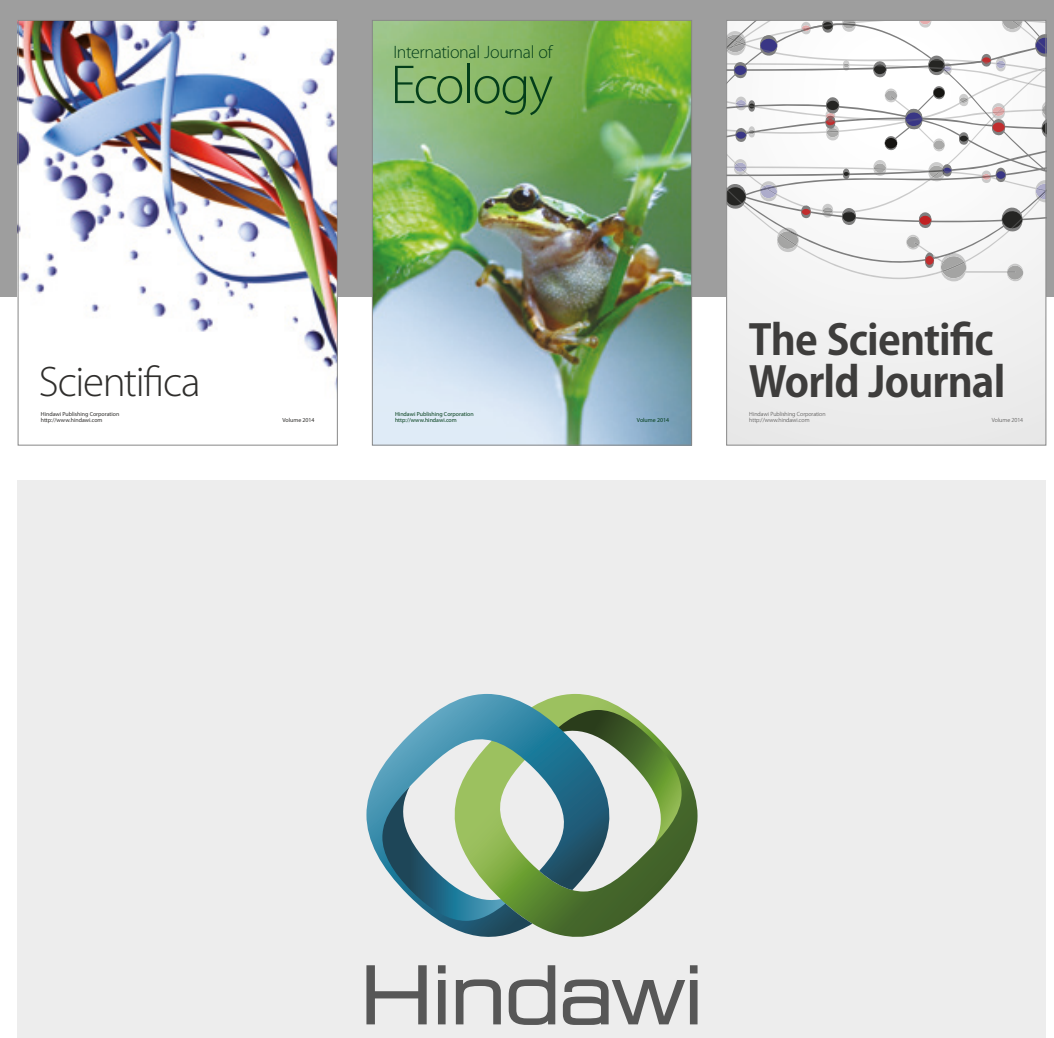

Submit your manuscripts at

https://www.hindawi.com
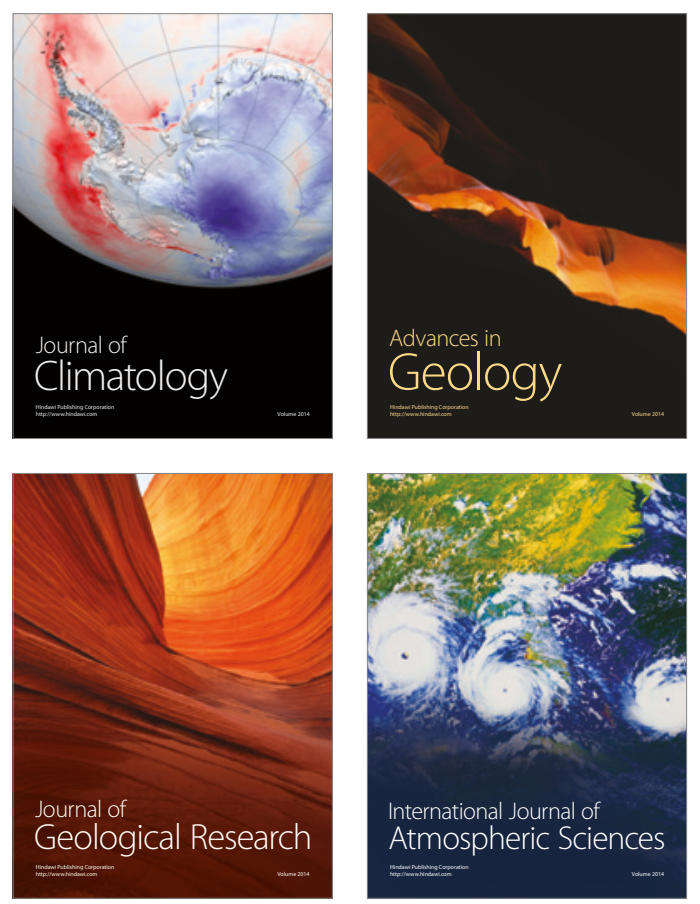

The Scientific

World Journal
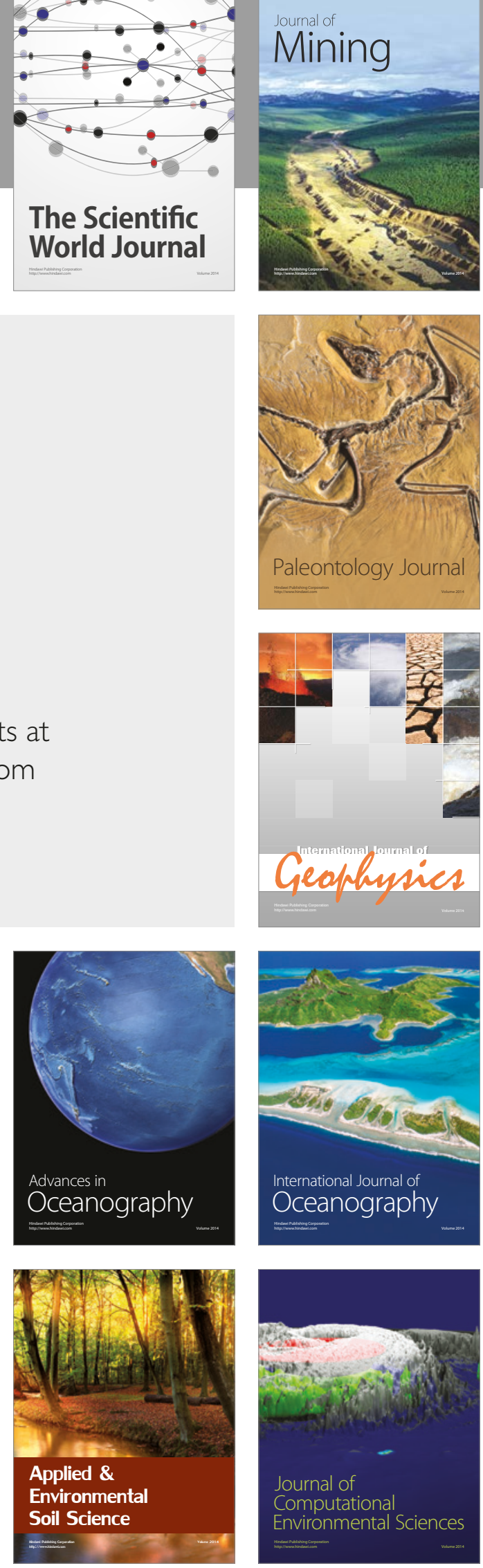